\title{
LUXendins reveal endogenous glucagon-like peptide-1 receptor distribution and dynamics
}

\begin{abstract}
Julia Ast ${ }^{1,2}$, Anastasia Arvaniti ${ }^{1,2}$, Nicholas H.F. Fine ${ }^{1,2}$, Daniela Nasteska ${ }^{1,2}$, Fiona B. Ashford $^{1,2}$, Zania Stamataki ${ }^{3}$, Zsombor Koszegi $i^{1,2}$, Andrea Bacon ${ }^{4}$, Stefan Trapp ${ }^{5}$, Ben J. Jones $^{6}$, Benoit Hastoy ${ }^{7}$, Alejandra Tomas ${ }^{8}$, Christopher A. Reissaus ${ }^{9}$, Amelia K. Linnemann $^{9}$, Elisa D'Este ${ }^{10}$, Davide Calebiro ${ }^{1,2}$, Kai Johnsson ${ }^{11}$, Tom Podewin ${ }^{11^{\star}}$, Johannes Broichhagen ${ }^{11^{*}}$ and David J. Hodson ${ }^{1,2^{*}}$

${ }^{1}$ Institute of Metabolism and Systems Research (IMSR), and Centre of Membrane Proteins and Receptors (COMPARE), University of Birmingham, Birmingham, UK.

2 Centre for Endocrinology, Diabetes and Metabolism, Birmingham Health Partners, Birmingham, UK.

3 Centre for Liver Research, College of Medical and Dental Sciences, Institute for Immunology and Immunotherapy, University of Birmingham, Birmingham, UK.

${ }^{4}$ Genome Editing Facility, Technology Hub, University of Birmingham, Birmingham, UK.

${ }^{5}$ Centre for Cardiovascular and Metabolic Neuroscience, Department of Neuroscience, Physiology \& Pharmacology, University College London, London, UK

6 Imperial College London, Section of Investigative Medicine, Division of Diabetes, Endocrinology and Metabolism, London, UK.

${ }^{7}$ Oxford Centre for Diabetes, Endocrinology \& Metabolism, University of Oxford, Oxford, UK

${ }^{8}$ Imperial College London, Section of Cell Biology and Functional Genomics, Division of Diabetes, Endocrinology and Metabolism, London, UK.

${ }^{9}$ Department of Pediatrics, Indiana University School of Medicine, Indianapolis, IN, USA.

${ }^{10}$ Optical Microscopy Facility, Max Planck Institute for Medical Research, Heidelberg, Germany.

${ }^{11}$ Department of Chemical Biology, Max Planck Institute for Medical Research, Heidelberg, Germany.
\end{abstract}

*Correspondence should be addressed to: d.hodson@bham.ac.uk, johannes.broichhagen@mpimf-heidelberg.mpg.de or $\quad$ tom.podewin@mpimfheidelberg.mpg.de

Keywords: incretin, diabetes, beta cell, alpha cell, fluorescent probes, CRISPR, nanoscopy.

Word count: 3534 (excluding Abstract, Methods, References and Legends). 


\section{ABSTRACT (150 words)}

44 The glucagon-like peptide-1 receptor (GLP1R) is a class B G protein-coupled receptor 45 (GPCR) involved in metabolism. Presently, its visualization is limited to genetic manipulation, 46 antibody detection or the use of probes that stimulate receptor activation. Herein, we present 47 LUXendin645, a far-red fluorescent GLP1R antagonistic peptide label. LUXendin645 48 produces intense and specific membrane labeling throughout live and fixed tissue. GLP1R 49 signaling can additionally be evoked when the receptor is allosterically modulated in the 50 presence of LUXendin645. Using LUXendin645 and STED-compatible LUXendin651, we 51 describe islet GLP1R expression patterns, reveal higher-order GLP1R organization including 52 the existence of membrane nanodomains, and track single receptor subpopulations. We 53 furthermore show that different fluorophores can confer agonistic behavior on the LUXendin 54 backbone, with implications for the design of stabilized incretin-mimetics. Thus, our labeling 55 probes possess divergent activation modes, allow visualization of endogenous GLP1R, and 56 provide new insight into class B GPCR distribution and dynamics. 


\section{INTRODUCTION}

The glucagon-like peptide-1 receptor (GLP1R) is a secretin family class B G protein-coupled receptor (GPCR) characterized by hormone regulation. ${ }^{1}$ Due to its involvement in glucose homeostasis, the GLP1R has become a blockbuster target for the treatment of type 2 diabetes mellitus. ${ }^{2}$ The endogenous ligand, glucagon-like peptide-1 (GLP-1) is released from enteroendocrine L-cells in the gut in response to food intake, ${ }^{3}$ from where it travels to the pancreas before binding to its cognate receptor expressed in $\beta$-cells. Following activation, the GLP1R engages a cascade of signaling pathways including $\mathrm{Ca}^{2+}, \mathrm{cAMP}, \mathrm{ERK}$ and $\beta-$ arrestin, which ultimately converge on $\beta$-cell survival and the glucose-dependent amplification of insulin release. ${ }^{4,5}$ GLP1R is also expressed in the brain ${ }^{6}$ and muscle ${ }^{7}$ where it further contributes to metabolism via effects on food intake, energy expenditure, locomotion and insulin sensitivity. Despite this, GLP1R localization remains a challenge and is impeding functional characterization of GLP-1 and drug action.

Chemical biology and recombinant genetics have made available a diverse range of methods for the visualization of biological entities. Thus, classical fluorescent proteinfusions, ${ }^{8}$ self-labeling suicide enzymes (SNAP-, CLIP-, and Halo-tag), ${ }^{9-11}$ "click chemistry"12,13 and fluorogenic probes $^{14-16}$ have provided unprecedented insight into the localization and distribution of their respective targets in living cells. In particular, current approaches for visualizing the GLP1R have so far relied on monoclonal antibodies (mAbs) directed against GLP1R epitopes, ${ }^{17,18}$ or fluorescent analogues of Exendin4(1-39), ${ }^{19-21}$ a stabilized form of GLP-1 and the basis for the incretin-mimetic class of drugs. Moreover, floxed mouse models exist in which Cre recombinase is driven by the Glp $1 r$ promoter, allowing labeling of GLP1R-expressing cells when crossed with reporter mice. ${ }^{6,7}$

Such methods have a number of shortcomings. Antibodies possess variable specificity ${ }^{18}$ and tissue penetration, and GLP1R epitopes might be hidden or preferentially affected by fixation in different cell types. Even more, fluorescent analogues of Exendin4(1-39) activate and internalize the receptor, which could confound results in live cells, particularly when used as a tool to sort purified populations (i.e. $\beta$-cells) for transcriptomic analysis. ${ }^{22,23}$ On the other hand, reporter mouse strategies possess high fidelity, but cannot account for posttranslational processing, protein stability and trafficking of native receptor. ${ }^{24}$ Lastly, none of the aforementioned approaches are amenable to super-resolution imaging of GLP1R.

Given the wider reported roles of GLP-1 signaling in the heart, ${ }^{25}$ liver,$~^{26}$ immune system ${ }^{2}$ and brain, ${ }^{27}$ it is clear that new tools are urgently required to help identify GLP-1 target sites, with repercussions for drug treatment and its side effects. In the present study, we therefore set out to generate a specific probe for endogenous GLP1R detection in its native, surfaceexposed state in live and fixed tissue, without receptor activation. Herein, we report LUXendin645 and LUXendin651, Cy5- and SiR- conjugated far-red fluorescent antagonists with unprecedented specificity, live tissue penetration and super-resolution capability. Using our tools, we provide an updated view of GLP1R expression patterns in the islet of Langerhans, show that endogenous GLP1Rs form nanodomains at the membrane and reveal receptor subpopulations with distinct diffusion modes. Lastly, we find that installation of a TMR fluorophore unexpectedly confers potent agonist properties. As such, the LUXendins provide the first nanoscopic characterization of a class B GPCR, with wider flexibility for detection and interrogation of GLP1R in the tissue setting. 


\section{RESULTS}

\section{Design and synthesis of LUXendin555, LUXendin651 and LUXendin645}

Ideally, a fluorescent probe to specifically visualize a biomolecule should have the following characteristics: straightforward synthesis and easy accessibility, high solubility, relative small size, high specificity and affinity, and a fluorescent moiety that exhibits photostability, brightness, (far-)red fluorescence with an additional two-photon cross-section. Moreover, the probe should be devoid of biological effects when applied to live cells and show good or no cell permeability, depending on its target localization. While some of these points were addressed in the past (vide infra), we set out to achieve this high bar by designing a highly specific fluorescent GLP1R antagonist using TMR, Cy5 and SiR fluorophores. As no small molecule antagonists for the GLP1R are known, we turned to Exendin4(9-39), a potent antagonistic scaffold amenable to modification (Fig. 1). ${ }^{28}$ We used solid-phase peptide synthesis (SPPS) to generate an S39C mutant, ${ }^{29}$ which provides a $C$-terminal thiol handle for late-stage installation of different fluorophores. As such, TMR-, Cy5- and SiR-conjugated versions were obtained by means of cysteine-maleimide chemistry, termed LUXendin555, LUXendin645, and LUXendin651, respectively (spectral properties are shown in Table 1, HPLC traces and HRMS characterization can be found in the SI) (Fig. 1).

Table 1: Spectral properties of GLP1R labeling probes. Maximal excitation and emission wavelengths, and quantum yields were acquired using probes dissolved at $10 \mu \mathrm{M}$ in PBS, pH 7.4 at $21^{\circ} \mathrm{C}$.

\begin{tabular}{|l|c|c|c|c|c|}
\hline & dye & $\lambda_{\mathrm{Ex}} / \mathbf{n m}$ & $\boldsymbol{\lambda}_{\mathrm{Em}} / \mathbf{n m}$ & $\boldsymbol{\varepsilon}^{[\mathrm{a}]} / \mathbf{M}^{-\mathbf{1}} \mathbf{c m}^{\mathbf{- 1}}$ & $\boldsymbol{\Phi}$ \\
\hline LUXendin555 & $\mathrm{TMR}$ & 555 & 579 & 84,000 & 0.31 \\
\hline LUXendin645 & $\mathrm{Cy} 5$ & 645 & 664 & 250,000 & 0.22 \\
\hline LUXendin651 & $\mathrm{SiR}$ & 651 & 669 & 100,000 & 0.43 \\
\hline
\end{tabular}

${ }^{[a]}$ For maleimide-conjugated fluorophores

\section{LUXendin645 intensely labels GLP1R in cells and tissue}

GLP-1-induced cAMP production $\left(E C_{50}(\mathrm{CAMP})=2.8 \mathrm{nM}, 95 \% \mathrm{Cl}[1.5-5.2]\right)$ was similarly blocked by Exendin4(9-39) $\left(E C_{50}(\mathrm{CAMP})=38.4 \mathrm{nM}, 95 \% \mathrm{Cl}[19.0-77.8]\right)$ and its $\mathrm{S} 39 \mathrm{C}$ mutant $\left(E C_{50}\right.$ (CAMP) $\left.=34.8 \mathrm{nM}, 95 \% \mathrm{Cl}[18.8-64.4]\right)$ (Fig. 2a). Installation of Cy5 to produce LUXendin645 did not affect these antagonist properties $\left(E C_{50}(\mathrm{cAMP})=73.1 \mathrm{nM}, 95 \% \mathrm{Cl}\right.$ [54.9-97.5]) (Fig. 2a). As expected, addition of the GLP1R positive allosteric modulator (PAM) BETP ${ }^{30}$ conferred agonist activity on LUXendin645 $\left(E C_{50}(\mathrm{CAMP})=9.3 \mathrm{nM}, 95 \% \mathrm{Cl}\right.$ [2.2-40.0]), with a potency similar to Exendin4(1-39) $\left(E C_{50}(\mathrm{CAMP})=18.3 \mathrm{nM}, 95 \% \mathrm{Cl}[8.0-\right.$ 42.1]) (Fig. 2b).

As a first assessment of GLP1R labeling efficiency, we probed YFP-AD293-SNAP_GLP1R cells with increasing concentrations of LUXendin645. Maximum labeling occurred at $100 \mathrm{nM}$ (Fig. 2c), in good agreement with the previously published $K_{d}=15.8 \mathrm{nM}$ of native Exendin4(9-39) ${ }^{31}$. LUXendin645 was unable to label YFP-AD293 cells in which the GLP1R was absent (Fig. 2d).

We next examined whether LUXendin645 would allow labeling of endogenous GLP1R. Following $60 \mathrm{~min}$ application of $50 \mathrm{nM}$ LUXendin645, isolated islets demonstrated intense and clean labeling, which was restricted to the membrane (Fig. 2e). Using conventional 
confocal microscopy, we were able to detect bright staining even $60 \mu \mathrm{m}$ into the islet (Fig. $2 \mathrm{e})$. Given these results, we next attempted to penetrate deeper into the islet by taking advantage of the superior axial resolution of two-photon excitation (Fig. 2f). Remarkably, this imaging modality revealed LUXendin645 labeling at high resolution throughout the entire volume of the islet (170 $\mu \mathrm{m}$ in this case) (Fig. 2f). Consistent with the cAMP assays, profound GLP1R internalization was detected following co-application of LUXendin645 and BETP to MIN6 $\beta$-cells, which endogenously express the receptor (Fig. 2g, h).

\section{LUXendin645 allows multiplexed GLP1R detection}

Demonstrating flexibility, LUXendin645 labeling was still present following formaldehyde fixation (Fig. 2i, j). Immunostaining using a specific primary monoclonal antibody against the GLP1R revealed strong co-localization with LUXendin645 in both islets (Fig. 2i) and MIN6 cells (Fig. 2j). Notably, LUXendin645 displayed superior signal-to-noise-ratio and membrane resolution compared to the antibody (Fig. 2k), expected to be even better in live tissue where auto-fluorescence is less. Likewise, LUXendin645 co-localized with SNAP-Surface 488 in SNAP_GLP1R-INS1 rat $\beta$-cells generated on an endogenous null background (Fig. 2I). Suggesting that LUXendin645 requires the presence of surface GLP1R, labeling was markedly reduced following prior internalization with Exendin4(1-39) (Fig. 2I, m).

\section{LUXendin645 specifically binds the GLP1R}

To further validate the specificity of LUXendin645 labeling in primary tissue, we generated Glp1r knock-out mice. This was achieved using CRISPR-Cas9 genome editing to introduce a deletion into exon 1 of the Glp1r. The consequent frameshift was associated with absence

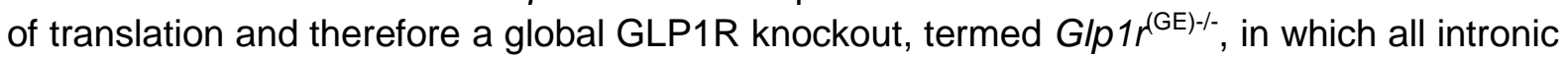
regions, and thus regulatory elements, are preserved (Fig. 3a, b). Wild-type $\left(G / p 1 r^{+/+}\right)$, heterozygous and homozygous littermates were phenotypically normal and possessed similar body weights (Fig. 3c).

Confirming successful GLP1R knock-out, insulin secretion assays in islets isolated from Glp1r(GE)-/ mice showed intact responses to glucose, but absence of Exendin4(1-39)stimulated insulin secretion (Fig. 3d). Reflecting this finding, the incretin-mimetic Liraglutide was only able to stimulate CAMP rises in islets from wild-type $\left(G / p 1 r^{+/+}\right)$littermates, measured using the FRET probe Epac2-camps (Fig. 3e, f). As expected, immunostaining with monoclonal antibody showed complete absence of GLP1R protein (Fig. 3g). Suggesting that LUXendin645 specifically targets GLP1R, with little to no cross-talk from glucagonreceptors, ${ }^{32}$ signal could not be detected in Glp $1 r^{(G E)-/}$ islets (Fig. $3 g$ ).

Together, these data provide strong evidence for a specific mode of LUXendin645 action via the GLP1R.

\section{LUXendin645 highlights weak GLP1R expression}

Previous approaches have shown low abundance of Glp $1 r$ transcripts in the other major islet endocrine cell type, i.e. glucagon-secreting $\alpha$-cells. ${ }^{7,33}$ This is associated with detection of GLP1R protein in $\sim 1-10 \%$ of cells, ${ }^{7,34}$ providing an excellent testbed for LUXendin645 sensitivity. Studies in intact islets showed that LUXendin645 labeling was widespread in the islet and well co-localized with insulin immunostaining (Fig. 4a). However, LUXendin645 could also be seen on membranes very closely associated with a-cells and somatostatin- 
secreting $\delta$-cells (Fig. 4b, c), similarly to results obtained with GLP1R mAb. Due to the close apposition of $\beta$-, $\alpha$ - and $\delta$-cell membranes, we were unable to accurately assign cell-type specificity to LUXendin645. Instead, using cell clusters plated onto coverslips, we could better discern LUXendin645 labeling, revealing GLP1R expression in $18 \pm 6 \%$ of $\alpha$-cells (Fig. 4d-f), higher than that shown before using antibodies ${ }^{19,34}$ and reporter genes ${ }^{7}$. Notably, GLP1R-expressing $\alpha$-cells tended to adjoin, whereas those without the receptor were next to $\beta$-cells. Confirming previous findings, a majority (86 $\pm 3 \%$ ) of $\beta$-cells were positive for LUXendin645 (Fig 4d-f)., ${ }^{7,19}$

We wondered whether fixation required for immunostaining might increase background fluorescence such that GLP1R detection specificity was reduced. To circumvent this, studies were repeated in live islets where LUXendin645 signal was found to be much brighter and background almost non-existent. GLP1R was detected in $26.2 \pm 1.1 \%$ of non- $\beta$-cells (Fig $4 \mathrm{~g}, \mathrm{~h}$ ) using Ins $1 \mathrm{Cre}{ }^{\text {Thor }} ; \mathrm{R}^{2} 6^{m T m G}$ reporter mice in which $\beta$-cells are labeled green and all other cell types are labeled red following Cre-mediated recombination. Once adjusted for the previously reported GLP1R expression in $\delta$-cells (assuming 100\%), which constitute $~ 20 \%$ of the insulin-negative islet population, ${ }^{35}$ this leaves $\sim 6 \%$ of GLP1R+ $\alpha$-cells. This was not an artefact of optical section, since two-photon islet reconstructions showed similar absence of LUXendin645 staining in discrete regions near the surface (where $\alpha$-cells predominate) (Movie S1).

\section{LUXendin645 and Luxendin651 reveal higher-order GLP1R organization}

By combining LUXendin645 with Super-Resolution Radial Fluctuations (SRRF) analysis, ${ }^{36}$ GLP1R could be imaged at super-resolution using streamed images ( 1000) from a conventional widefield microscope (Fig. 5a). To image endogenous GLP1R at $<100 \mathrm{~nm}$ lateral resolution, we combined STED nanoscopy with LUXendin651, which bears silicon rhodamine ( $\mathrm{SiR}$ ) instead of Cy5. LUXendin651 produced bright labeling of wild-type but not Glp $1 r^{(G E)-/-}$ islets, with an identical distribution to LUXendin645 (Supplementary Fig. S1). Incubation of MIN6 cells with LUXendin651 and subsequent fixation allowed STED imaging of the endogenous GLP1R with a FWHM $=70 \pm 10 \mathrm{~nm}$ (Fig. 5b, c). STED snapshots of MIN6 $\beta$-cells revealed GLP1R distribution with unprecedented detail: receptors were not randomly arranged but rather tended to organize into nanodomains with neighbors (Fig. 5b, c). This was confirmed using the F- and G-functions, which showed a non-random and more clustered GLP1R distribution (Fig. 5d, e). Differences in GLP1R expression level and pattern could clearly be seen between neighboring cells with a subpopulation possessing highly concentrated GLP1R clusters (Fig. 5f).

Finally, to test whether LUXendin645 and LUXendin651 would be capable of tracking GLP1Rs in live cells, we performed single-molecule microscopy experiments in which individual receptors labeled with either fluorescent probe were imaged by total internal reflection fluorescence (TIRF) microscopy. ${ }^{37,38}$ Both probes allowed GLP1R to be tracked at the single-molecule level in CHO-K1-SNAP_GLP1R cells, but brightness and bleaching precluded longer recordings with LUXendin645 (Fig. $5 \mathrm{~g}$ and Supplementary Movies S2, S3). By combining single-particle tracking with LUXendin651, we were able to show that most GLP1Rs diffuse rapidly at the membrane (Fig. $5 \mathrm{~g}$ and Supplementary Movie S4). However, a mean square displacement (MSD) analysis ${ }^{37}$ revealed a high heterogeneity in the diffusion of GLP1Rs on the plasma membrane, ranging from virtually immobile receptors to some displaying features of directed motion (superdiffusion) (Fig. 5h). 


\section{Altering fluorophore to produce LUXendin555 confers different ligand behavior}

229 Lastly, we explored whether swapping the far-red Cy5/SiR for a TMR dye would be tolerated 230 to obtain a spectrally orthogonal probe, termed LUXendin555. Labeling was detected in 231 YFP-AD293-SNAP_GLP1R (Fig. 6a) but not YFP-AD293 cells (Fig. 6b). However, we 232 noticed a more punctate LUXendin555 staining pattern when viewed at high-resolutions 233 (Fig. 6c). Further experiments with MIN6 cells and islets showed similar internalization of the 234 GLP1R (Fig. 6d), suggesting that LUXendin555 acts as an agonist, presumably via 235 interactions mediated by the ectodomain. This was confirmed using CAMP assays where 236 LUXendin555 was found to potently activate GLP1R signaling $\left(E C_{50}(C A M P)=129.8 \mathrm{nM}\right.$; $23795 \% \mathrm{Cl}=56.9-296.2$ ) (Fig. 6e). Intriguingly, LUXendin555 potency could be further 238 increased using a PAM $\left(E C_{50}(\mathrm{CAMP})=28.4 \mathrm{nM} ; 95 \% \mathrm{Cl}=11.3-71.8\right)$ (Fig. 6f), suggesting a 239 unique binding conformation at the orthosteric site compared to agonists such as 240 Exendin4(1-39), which cannot be allosterically-modulated. ${ }^{30}$ As for the other probes, 241 LUXendin555 was unable to label Glp $1 r^{(\text {GE)-l }}$ islets (Fig. S2).

\section{LUXendins label islets in vivo}

243 We thought that the high quantum yield of TMR, coupled with good two-photon cross-section 244 and agonistic behaviour might suit LUXendin555 well to in vivo imaging where maintenance 245 of normoglycemia under anaesthesia can be an advantage for some experiments. Twophoton imaging was applied to an anaesthetized mouse to allow visualization of the intact pancreas, exposed through an abdominal incision (Fig. 6g). Vessels and nuclei were first labeled using FITC-dextran and Hoechst before injecting LUXendin555 intravenously. Labeling occurred rapidly within 5 min post-injection, produced intense membrane staining confined to the islet where GLP1R is expressed (Fig. 6h), and normoglycemia was maintained $(250 \mathrm{mg} / \mathrm{dl})$. No obvious internalization could be seen, most likely reflecting the time of exposure to LUXendin555, as well as the concentration achieved in vivo at the islet. 
254 In the present study, we synthesize and validate far-red fluorescent labels, termed 255 LUXendins for the real-time detection of GLP1R in live cells. Nanomolar concentrations of 256 LUXendin645 and LUXendin651 led to intense membrane-labeling of the GLP1R, with best in class tissue penetration and signal-to-noise ratio, as well as super-resolution capability. Notably, LUXendin645 and LUXendin651 did not activate the GLP1R unless agonist activity is conferred with the widely-available PAM BETP. LUXendin645 and LUXendin651 are highly specific, as shown using a novel CRISPR-Cas9 mouse line lacking GLP1R expression. Lastly, the analogous compound LUXendin555 bearing a different fluorophore unusually displays agonistic activity, expanding the color palette and activity profile without changing the peptidic pharmacophore.

Compared to present chemical biology approaches, LUXendins possess a number of advantages for GLP1R labeling, which generally rely on Exendin4(1-39) labeled with for instance Cy3, Cy5 or FITC. ${ }^{19-21,30}$ Firstly, the use of an antagonist encourages receptor recycling back to the membrane and retains receptor at the cell surface, which likely increases detection capability. Secondly, the GLP1R is not activated, meaning that results can be interpreted in the absence of potentially confounding cell signaling, such as that expected with agonists. ${ }^{19}$ Thirdly, Cy5 occupies the far-red range, leading to less background fluorescence, increasing depth penetration due to reduced scatter, and avoiding the use of more phototoxic wavelengths. ${ }^{39}$ Together, these desirable properties open up the possibility to image expression and trafficking of native GLP1R over extended periods of time, when LUXendins are used in conjunction with a PAM.

To test the specificity of LUXendins, we used CRISPR-Cas9 genome-editing to globally knock out the GLP1R in mice. Protein deletion was confirmed by absence of detectable GLP1R signal following labeling with monoclonal antibody, LUXendin555, LUXendin645 and LUXendin651. While Glp $1 r^{-1}$ animals already exist and have made important contributions to our understanding of incretin biology, they were produced using a targeted mutation to replace exons encoding transmembrane regions 1 and 3 (encoded by exons 5 and 7), presumably leading to deletion of the introns in between ( 6.25 kb). ${ }^{40}$ By contrast, Glp $1 r^{(\mathrm{GE})-/}$ mice possess intact introns. Since introns contain regulatory elements, such as distant-acting enhancers ${ }^{41}$, miRNAs ${ }^{42}$ and IncRNAs, ${ }^{43}$ their loss in transgenic knockouts could have wider influence on the transcriptome. GLP1R knock-out mice might therefore be useful alongside conventional approaches for validating GLP1R reagents, including antibodies, agonist and antagonist, and derivatives thereof.

Demonstrating the excellent sensitivity of the Cy5-linked LUXendin645 in particular, we were able to detect GLP1R in $\sim 6-18 \%$ of $\alpha$-cells. Understanding $\alpha$-cell GLP1R expression patterns is important because incretin-mimetics reduce glucagon secretion, ${ }^{44}$ which would otherwise act to aggravate blood glucose levels. However, previous studies using antibodies, reporter animals and agonist-fluorophores have shown $\sim 1-10 \%$ GLP1R expression in mouse and rat $\alpha$-cells, in line with the low transcript abundance ${ }^{7,19,33,45}$, despite reports that GLP-1 can directly suppress glucagon release. ${ }^{34,46}$ Our data are in general concordance with these findings, but demonstrate an increase in detection capability for native GLP1R. This improvement is likely related to the superior SNR of LUXendin645 compared to $\mathrm{mAb}$ and agonist-fluorophore, increasing the ability to resolve relatively low 
antibody raised against the $\mathrm{N}$-terminal region, with both membrane and cytosolic staining evident ${ }^{47}$. While the reasons for this discrepancy are unknown, it should be noted that LUXendin645 binds the orthosteric site and so reports the proportion of GLP1R that is "signaling competent". 7, 19, 32 .

Since LUXendin645 showed excellent signal-to-noise ratio using conventional epifluorescence, it was highly amenable to SRRF analysis. As such, LUXendin645 and its congeners open up the possibility to image the GLP1R at super-resolution using simple widefield microscopy available in most laboratories. For stimulated emission depletion (STED) microscopy experiments, Cy5 was replaced with SiR to give LUXendin651. STED imaging showed that endogenous GLP1R possess a higher structural order, namely organization into nanodomains at the cell membrane. The presence of nanodomains under non-stimulated conditions might reflect differences in palmitoylation, which has recently been shown to influence GLP1R membrane distribution in response to agonists. ${ }^{48}$ Notably, a subpopulation of $\beta$-cells appeared to possess highly-concentrated GLP1R clusters. It will be important in the future to investigate whether this is a cell autonomous heterogenous trait, or instead reflects biased orientation of membranes toward specific $\beta$-cells. Lastly, both LUXendin645 and LUXendin651 allowed GLP1Rs to be imaged in live cells by singlemolecular microscopy, revealing variability in their diffusion at the plasma membrane. Particle tracking analyses segregated GLP1R into four different populations based upon diffusion mode, in keeping with data from beta adrenergic receptors. ${ }^{37}$ Together, these experiments provide the first super-resolution characterization of a class B GPCR and suggest a degree of complexity not readily appreciated with previous approaches.

Intriguingly, we saw that swapping Cy5 for a TMR moiety to give LUXendin555 completely changed the pharmacological behavior. The reasons for this are unknown, but we speculate that the rhodamine scaffold engages a secondary binding site in the GLP1R ectodomain, leading to activation. This finding is remarkable because it suggests that the agonist $\rightarrow$ antagonist switch that occurs following removal of eight $\mathrm{N}$-terminal amino acids (as physiologically mediated by the protease DPP-4) ${ }^{49}$ can be counteracted simply by installing a $C$-terminal linked rhodamine fluorophore, with implications for the design of more stable GLP1R activators. More generally, this shift in compound behaviour following a fluorophore modification serves as another instructive example for the thorough validation of all new chemical labels. ${ }^{50}$ Nonetheless, LUXendin555 possessed advantageous properties for in vivo imaging including maintenance of relatively stable glycemia, good two-photon crosssection and high quantum yield.

In summary, we provide a comprehensively-tested and unique GLP1R detection toolbox consisting of far-red antagonist labels, LUXendin645 and LUXendin651, an agonist LUXendin555, and knockout G/p1r (GE)-- animals. Using these freely-available probes, we provide an updated view of GLP1R organization, with relevance for the treatment of complex metabolic diseases such as obesity and diabetes, as well as production of more stable GLP1R activators. Thus, the stage is set for visualizing GLP1R in various tissues using a range of imaging techniques, as well as the production of novel peptidic labels and agonists. 


\section{METHODS}

341

342

343

\section{Synthesis}

Solid-phase peptide synthesis of S39C-Exendin4(9-39) was performed as previously reported. $^{29}$ Maleimide-conjugated-6-TMR, -6-SiR and -Cy5 were obtained by TSTU activation of the corresponding acids and reaction with 1-(2-amino-ethyl)-pyrrole-2,5-dione (TFA salt, Aldrich). Fluorophore coupling via thiol-maleimide chemistry to peptides was performed in PBS. All compounds were characterized by HRMS and purity was assessed to be $>95 \%$ by HPLC. Extinction coefficients were based upon known manufacturer bulk material measures for TMR-Mal, Cy5-Mal (both Lumiprobe) and SiR-Mal (Spirochrome). Details for synthesis including further characterization of all LUXendins are detailed in the Supporting Information. LUXendin555, LUXendin651 and LUXendin645 are freely available for academic use upon request.

\section{Cell culture}

AD293 cells (Agilent) were maintained in Dulbecco's Modified Eagles medium (DMEM) supplemented with $10 \%$ fetal calf serum (FCS), $1 \%$ L-glutamine and $1 \%$ penicillin/streptomycin. CHO-K1 cells (a kind gift from $\mathrm{Dr}$ Ben Jones, Imperial College London) stably expressing the human SNAP_GLP1R (Cisbio) (CHO-K1-SNAP_GLP1R) were maintained in DMEM supplemented with $10 \%$ FCS, $1 \%$ penicillin/streptomycin, 500 $\mu \mathrm{g} / \mathrm{mL}$ G418, $5 \mathrm{mM}$ D-glucose, $10 \mathrm{mM}$ HEPES and 1\% nonessential amino acids. MIN6 $\beta$ cells (a kind gift from Prof. Jun-ichi Miyazaki, Osaka University) were maintained in DMEM supplemented with 15\% FCS, $25 \mathrm{mM}$ D-glucose, $71 \mu \mathrm{M}$ BME, $2 \mathrm{mM}$ L-glutamine, $100 \mathrm{U} / \mathrm{mL}$ penicillin, and $100 \mu \mathrm{g} / \mathrm{mL}$ streptomycin. INS1 832/3 CRISPR-deleted for the endogenous GLP1R locus (a kind gift from Dr. Jacqui Naylor, Medlmmune) ${ }^{51}$ were transfected with human SNAP_GLP1R, before FACS of the SNAP-Surface488-positive population and selection using G418. ${ }^{48}$ The resulting SNAP_GLP1R_INS1 ${ }^{\text {GLP1R-/ }}$ cells were maintained in RPMI-1640 supplemented with 10\% FBS, $10 \mathrm{mM}$ HEPES, $2 \mathrm{mM}$ L-glutamine, $1 \mathrm{mM}$ pyruvate, $72 \mu \mathrm{M} \beta$-mercaptoethanol, $1 \%$ penicillin/streptomycin and $500 \mu \mathrm{g} / \mathrm{mL}$ G418.

\section{Animals}

GIp1r(GE)-- $:$ CRISPR-Cas9 genome-editing was used to introduce a single base pair deletion into exon 1 of the Glp1r locus. Fertilized eggs of female Cas9-overexpressing mice (strain $\left.G t(R O S A) 26 S^{t m 1.1\left(C A G-c a s 9^{*},-E G F P\right) F e z h} / \mathrm{J}\right)$ were harvested following super-ovulation. Modified single-guide RNA (Synthego) targeting exon 1 of Glp1r and a single-stranded repairtemplate were injected at $20 \mathrm{ng} / \mu \mathrm{l}$ into the pronucleus of embryos at the 1 -cell stage. In culture, $80 \%$ of embryos reached the 2-cell stage and were transplanted into surrogate mice. The targeted locus of offspring was analyzed by PCR and sequencing. Besides the insertion of the repair template, deletions of up to 27 nucleotides could be detected in 2 out of 6 offspring. Design of the repair template will be described elsewhere. Off-target sites were predicted using the CRISPR Guide Design Tool (crispr.mit.edu). Loci of the top ten off-target hits were amplified by PCR and analyzed via Sanger sequencing. Founder animals carrying alleles with small deletions were backcrossed to wild type animals (strain C57BL/6J) for 1-2 generations to outbreed affected off-targets and then bred to homozygosity. Animals with the larger deletion of 27 nucleotides were not taken forward, as GLP1R protein was still present. Animals were born in Mendelian ratios and genotyping was performed using Sanger 
sequencing. Animals were bred as heterozygous pairs to ensure $G / p 1 r^{+/+}$littermates. Glp $1 r^{(\mathrm{GE})-l_{-}}$animals are freely available for academic use, subject to a Material Transfer Agreement.

Ins1Cre ${ }^{\text {Thor }} ; R 26^{m T / m G}$ : To allow identification of $\beta$ - and non- $\beta$-cells, Ins $1 C r e^{\text {Thor }}$ animals with

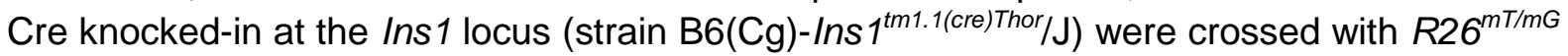

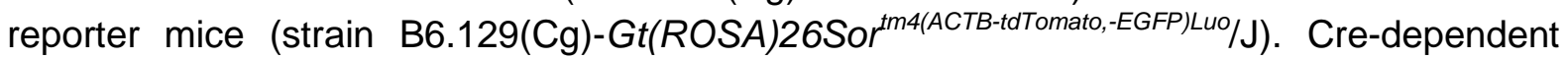
excision of the floxed allele results in deletion of tdTomato, expression of membranelocalized GFP and thus identification of recombined and non-recombined cells.

All studies were performed with 6-12 week old male and female animals, and regulated by the Animals (Scientific Procedures) Act 1986 of the U.K. Approval was granted by the University of Birmingham's Animal Welfare and Ethical Review Body.

\section{Islet isolation}

Islets were isolated from male and female Glp $1 r^{(G E)-/-}$ and Ins $1 C r e^{T h o r} ; R 26^{m T / m G}$ mice, as well as CD1 wild-type animals, maintained under specific-pathogen free conditions, with ad lib access to food and water. Briefly, animals were humanely euthanized before injection of collagenase $1 \mathrm{mg} / \mathrm{mL}$ (Serva NB8) into the bile duct. Following removal of the inflated pancreas and digestion for $12 \mathrm{~min}$ at $37{ }^{\circ} \mathrm{C}$, islets were separated using a Histopaque (Sigma-Aldrich) gradient. Islets were cultured in RPMI medium containing 10\% FCS, 100 units $/ \mathrm{mL}$ penicillin, and $100 \mu \mathrm{g} / \mathrm{mL}$ streptomycin.

\section{Binding and potency assays}

Binding assays were performed in transiently-transfected YFP-AD293-SNAP_GLP1R cells (using PolyJet reagent; SignaGen). Increasing concentrations of compound were applied for $60 \mathrm{~min}$, before imaging using a Zeiss LSM880 meta-confocal microscope configured with GaAsP detectors and $10 \times / 0.45 \mathrm{~W}, 40 \mathrm{x} / 1.00 \mathrm{~W}$ and $63 \times / 1.20 \mathrm{~W}$ objectives. YFP, TMR (LUXendin555) and Cy5 (LUXendin645) were excited using $\lambda=514 \mathrm{~nm}, \lambda=561 \mathrm{~nm}$ and $\lambda$ $=633 \mathrm{~nm}$ lasers, respectively. Emitted signals were captured at $\lambda=519-574 \mathrm{~nm}, \lambda=570$ $641 \mathrm{~nm}$ and $\lambda=638-759 \mathrm{~nm}$ for YFP, TMR (LUXendin555) and Cy5 (LUXendin645), respectively. Control experiments were performed in YFP-AD293-SNAP cells, as above.

Potency for CAMP generation and inhibition was tested in heterologous expression systems, comprising either stable CHO-K1-SNAP_GLP1R cells or transiently-transfected YFPAD293-SNAP_GLP1R cells, as previously described. ${ }^{29}$ Briefly, cells were incubated with increasing concentrations of compound +/- allosteric modulator for $30 \mathrm{~min}$, before harvesting, lysis and measurement of CAMP using CAMP-GIO ${ }^{\mathrm{TM}}$ Assay (Promega), according to the manufacturer's instructions. $E C_{50}$ values were calculated using log concentrationresponse curves fitted with a three-parameter equation.

\section{Live imaging}

Islets were incubated for $1 \mathrm{~h}$ at $37^{\circ} \mathrm{C}$ in culture medium supplemented with either $100-250$ nM LUXendin555, 50-100 nM LUXendin645 or 100 nM LUXendin651, based upon binding assays. Islets were imaged using either a Zeiss LSM780 or LSM880 microscope, as above (LUXendin651 was imaged as for LUXendin645). Ins $1 \mathrm{Cre}^{T h o r} ; R 26^{m T / m G}$ islets were excited at $\lambda=488 \mathrm{~nm}$ (emission, $\lambda=493-555 \mathrm{~nm}$ ) and $\lambda=561 \mathrm{~nm}$ (emission, $\lambda=570-624 \mathrm{~nm}$ ) for 
mGFP and tdTomato, respectively. Two-photon imaging of LUXendin645 was performed using a Zeiss LSM 880 NLO equipped with a Spectra-Physics Insight X3 femtosecondpulsed laser and 20x/1.00 W objective. Excitation was performed at $\lambda=800 \mathrm{~nm}$ and emitted signals detected at $\lambda=638-759 \mathrm{~nm}$.

\section{cAMP imaging}

Islets were transduced with adenovirus harboring the FRET sensor, Epac2-camps, before imaging using a Crest $\mathrm{X}$-Light spinning disk system coupled to a Nikon Ti-E base and 10x/0.4 NA objective. Excitation was delivered at $\lambda=430-450 \mathrm{~nm}$ using a Lumencor Spectra $X$ light engine. Emitted signals were detected at $\lambda=460-500$ and $\lambda=520-550 \mathrm{~nm}$ for Cerulean and Citrine, respectively, using a Photometrics Delta Evolve EM-CCD. Imaging was performed in HEPES-bicarbonate buffer, containing (in mmol/L) $120 \mathrm{NaCl}, 4.8 \mathrm{KCl}, 24$ $\mathrm{NaHCO}_{3}, 0.5 \mathrm{Na}_{2} \mathrm{HPO}_{4}, 5 \mathrm{HEPES}, 2.5 \mathrm{CaCl}_{2}, 1.2 \mathrm{MgCl}_{2}$, and 3-17 D-glucose. Vehicle $\left(\mathrm{H}_{2} \mathrm{O}\right)$, Exendin4(1-39) (10-20 nM) or Liraglutide (10 nM) were applied at the indicated time points, with forskolin $(10 \mu \mathrm{M})$ acting as a positive control.

\section{Immunostaining}

LUXendin555- or LUXendin645-treated cells or tissue were fixed for $60 \mathrm{~min}$ in $4 \%$ paraformaldehyde. Primary antibodies were applied overnight at $4{ }^{\circ} \mathrm{C}$ in PBS $+0.1 \%$ Triton $+1 \%$ BSA. Secondary antibodies were applied in the same buffer for $1 \mathrm{~h}$ at room temperature, before mounting on slides using Vectashield Hardset containing DAPI. Primary antibodies were mouse monoclonal anti-GLP1R 1:30 (lowa DHSB; mAb \#7F38), rabbit antiinsulin 1:500 (Cell Signaling Technology, \#3014), mouse monoclonal anti-glucagon 1:2000 (Sigma-Aldrich, \#G2654) and mouse anti-somatostatin 1:5000 (Invitrogen, \#14-9751-80). Secondary antibodies were goat anti-mouse Alexa Fluor 568 and donkey anti-rabbit DyLight 488 1:1000. Images were captured using an LSM880 meta-confocal microscope. Alexa Fluor 488 and Alexa Fluor 568 were excited at $\lambda=488 \mathrm{~nm}$ and $\lambda=568 \mathrm{~nm}$, respectively. Emitted signals were detected at $\lambda=500-550 \mathrm{~nm}$ (Alexa Fluor 488) and $\lambda=519-574 \mathrm{~nm}$ (Alexa Fluor 568).

\section{Super-resolution microscopy}

SRRF: MIN6 were treated with LUXendin645 before fixation and mounting on slides using Vectashield Hardset containing DAPI. Imaging was performed using a Crest X-Light spinning disk system in bypass (widefield) mode. Excitation was delivered at $\lambda=640 / 30 \mathrm{~nm}$ through a $63 \times / 1.4$ NA objective using a Lumencor Spectra $X$ light engine. Emission was collected at $\lambda=700 / 75 \mathrm{~nm}$ using a Photometrics Delta Evolve EM-CDD. A 1000 image sequence was captured ( $2 \mathrm{~min}$ ) before offline super resolution radial fluctuation (SRRF) analysis to generate a single super-resolution snapshot using the NanoJ plugin for ImageJ (NIH). ${ }^{36}$

Stimulated emission depletion (STED) microscopy: MIN6 cells were treated with 100, 200 and $400 \mathrm{nM}$ LUXendin651 before fixation (4\% paraformaldehyde, $20 \mathrm{~min}$ ). Cells were mounted in Mowiol supplemented with DABCO and imaged on an Abberior STED 775/595/RESOLFT QUAD scanning microscope (Abberior Instruments GmbH, Germany) equipped with STED lines at $\lambda=595$ and $\lambda=775 \mathrm{~nm}$, excitation lines at $\lambda=355 \mathrm{~nm}, 405 \mathrm{~nm}$, $485 \mathrm{~nm}, 561 \mathrm{~nm}$, and $640 \mathrm{~nm}$, spectral detection, and a UPlanSApo 100x/1.4 oil immersion objective lens. Following excitation at $\lambda=640 \mathrm{~nm}$, fluorescence was acquired in the spectral 
window $\lambda=650-800 \mathrm{~nm}$. Deconvolution was performed with Richardson-Lucy algorithm on Imspector software. FWHM was measured on raw data and calculated using OriginPro 2017 software with Gaussian fitting ( $\mathrm{n}=15$ profiles). Spatial GLP1R expression patterns were analyzed using the $\mathrm{F}$ - and $\mathrm{G}$-functions, where $\mathrm{F}=$ distance between an object of interest and its nearest neighbor, and $\mathrm{G}=$ distance from a given position to the nearest object of interest (FIJI Spatial Statistic 2D/3D plugin). ${ }^{52}$ Both measures were compared to a random distribution of the same measured objects, with a shift away from the mean $+/-95 \%$ confidence intervals indicating a non-random or clustered organization (i.e. more space or smaller distance between objects).

Single-molecule microscopy: For single-molecule experiments, CHO-K1-SNAP_GLP1R cells were seeded onto $25 \mathrm{~mm}$ clean glass coverslips at a density of $3 \times 10^{5}$ per well. On the following day, cells were labeled in culture medium with $100 \mathrm{pM}$ LUXendin645 or LUXendin651 for $20 \mathrm{~min}$. At the end of the incubation, cells were washed $3 \times 5 \mathrm{~min}$ in culture medium. Cells were then imaged at $37^{\circ} \mathrm{C}$ in phenol-red free Hank's balanced salt solution, using a custom built total internal reflection fluorescence microscope (Cairn Research) based on an Eclipse Ti2 (Nikon, Japan) equipped with an EMCCD camera (iXon Ultra, Andor), $637 \mathrm{~nm}$ diode laser, and a 100x oil-immersion objective (NA 1.49, Nikon). Image sequences were acquired with an exposure time of $60 \mathrm{~ms}$. Single-molecule image sequences were analyzed with an automated particle detection software (utrack) in the MATLAB environment, as previously described. ${ }^{53,54}$. Data were further analyzed using custom MATLAB algorithms, as previously described. ${ }^{37,55}$

\section{Two-photon in vivo imaging}

A 7 week old female C57BL/6J mouse was anesthetized with isoflurane and a small, $1 \mathrm{~cm}$ vertical incision was made at the level of the pancreas. The exposed organ was orientated underneath the animal and pressed against a $50 \mathrm{~mm}$ glass-bottom dish for imaging on an inverted microscope. Body temperature was maintained using heat pads and heating elements on the objective. The mouse received Hoechst 33342 (1 mg/kg in PBS) to label nuclei, a $150 \mathrm{kDalton}$ fluorescein-conjugated dextran (1 $\mathrm{mg} / \mathrm{kg}$ in PBS) to label vasculature, and $75 \mathrm{uL}$ of $30 \mu \mathrm{M}$ LUXendin555 via retro-orbital IV injection. Images were collected using a Leica SP8 microscope, equipped with a 25x/0.95 NA objective and Spectra Physics MaiTai DeepSee mulitphoton laser. Excitation was delivered at $\lambda=850 \mathrm{~nm}$, with signals collected with a HyD detector at $\lambda=460 / 50, \lambda=525 / 50, \lambda=624 / 40 \mathrm{~nm}$ for Hoechst, FITC and LUXendin555, respectively. All in vivo imaging experiments were performed with approval and oversight from the Indiana University Institutional Animal Care and Use Committee (IACUC).

\section{Statistical analyses}

Measurements were performed on discrete samples unless otherwise stated. All analyses were conducted using GraphPad Prism software. Unpaired or paired Students t-test was used for pairwise comparisons. Multiple interactions were determined using one-way ANOVA followed by Dunn's or Sidak's posthoc tests (accounting for degrees of freedom). 
bioRxiv preprint doi: https://doi.org/10.1101/557132; this version posted May 8, 2019. The copyright holder for this preprint (which was not certified by peer review) is the author/funder, who has granted bioRxiv a license to display the preprint in perpetuity. It is made available under aCC-BY-NC-ND 4.0 International license.

\section{Data availability}

509 The datasets generated during and/or analysed during the current study are available from 510 the corresponding author on reasonable request. 


\section{REFERENCES}

513 1. Baggio, L.L. \& Drucker, D.J. Biology of incretins: GLP-1 and GIP. Gastroenterology

2. Campbell, J.E. \& Drucker, D.J. Pharmacology, physiology, and mechanisms of incretin hormone action. Cell Metab 17, 819-837 (2013).

3. Parker, H.E. et al. Molecular mechanisms underlying bile acid-stimulated glucagonlike peptide-1 secretion. British Journal of Pharmacology 165, 414-23 (2012).

4. Leech, C.A. et al. Molecular physiology of glucagon-like peptide-1 insulin secretagogue action in pancreatic beta cells. Progress in Biophysics and Molecular Biology 107, 236-47 (2011).

5. MacDonald, P.E. et al. The multiple actions of GLP-1 on the process of glucosestimulated insulin secretion. Diabetes 51 Suppl 3, S434-42 (2002).

6. Cork, S.C. et al. Distribution and characterisation of Glucagon-like peptide-1 receptor expressing cells in the mouse brain. Mol Metab 4, 718-31 (2015).

7. Richards, P. et al. Identification and Characterization of GLP-1 Receptor-Expressing Cells Using a New Transgenic Mouse Model. Diabetes 63, 1224-1233 (2013).

8. Giepmans, B.N., Adams, S.R., Ellisman, M.H. \& Tsien, R.Y. The fluorescent toolbox for assessing protein location and function. Science 312, 217-24 (2006).

9. Yang, G. et al. Genetic targeting of chemical indicators in vivo. Nat Methods 12, 137139 (2015).

10. Lukinavičius, G. et al. A near-infrared fluorophore for live-cell super-resolution microscopy of cellular proteins. Nature Chemistry 5, 132-139 (2013).

11. Los, G.V. et al. HaloTag: A Novel Protein Labeling Technology for Cell Imaging and Protein Analysis. ACS Chemical Biology 3, 373-382 (2008).

12. Lang, K. et al. Genetic Encoding of Bicyclononynes and trans-Cyclooctenes for SiteSpecific Protein Labeling in Vitro and in Live Mammalian Cells via Rapid Fluorogenic Diels-Alder Reactions. Journal of the American Chemical Society 134, 10317-10320 (2012).

13. Jewett, J.C. \& Bertozzi, C.R. Cu-free click cycloaddition reactions in chemical biology. Chem Soc Rev 39, 1272-9 (2010).

14. Lukinavicius, G. et al. Fluorogenic Probes for Multicolor Imaging in Living Cells. J Am Chem Soc 138, 9365-8 (2016).

15. Lukinavicius, G. et al. Fluorogenic probes for live-cell imaging of the cytoskeleton. Nat Methods 11, 731-3 (2014).

16. Karch, S. et al. A New Fluorogenic Small-Molecule Labeling Tool for Surface Diffusion Analysis and Advanced Fluorescence Imaging of $\beta$-Site Amyloid Precursor Protein-Cleaving Enzyme 1 Based on Silicone Rhodamine: SiR-BACE1. Journal of Medicinal Chemistry 61, 6121-6139 (2018).

17. Pyke, C. et al. GLP-1 receptor localization in monkey and human tissue: novel distribution revealed with extensively validated monoclonal antibody. Endocrinology 155, 1280-90 (2014).

18. Pyke, C. \& Knudsen, L.B. The glucagon-like peptide-1 receptor--or not? Endocrinology 154, 4-8 (2013).

19. Lehtonen, J., Schäffer, L., Rasch, M.G., Hecksher-Sørensen, J. \& Ahnfelt-Rønne, J. Beta cell specific probing with fluorescent exendin-4 is progressively reduced in type 2 diabetic mouse models. Islets 7, e1137415 (2016).

20. Clardy, S.M. et al. Fluorescent Exendin-4 Derivatives for Pancreatic $\beta$-Cell Analysis. Bioconjugate Chemistry 25, 171-177 (2013).

21. Clardy, S.M. et al. Rapid, high efficiency isolation of pancreatic ss-cells. Sci Rep 5, 13681 (2015).

22. Kleiner, S. et al. Mice harboring the humanSLC30A8R138X loss-of-function mutation have increased insulin secretory capacity. Proceedings of the National Academy of Sciences 115, E7642-E7649 (2018). 
23. Kim, J. et al. Amino Acid Transporter Slc38a5 Controls Glucagon Receptor InhibitionInduced Pancreatic a Cell Hyperplasia in Mice. Cell Metabolism 25, 1348-1361.e8 (2017).

24. Aroor, A. \& Nistala, R. Tissue-Specific Expression of GLP1R in Mice: Is the Problem of Antibody Nonspecificity Solved? Diabetes 63, 1182-1184 (2014).

25. Drucker, Daniel J. The Cardiovascular Biology of Glucagon-like Peptide-1. Cell Metabolism 24, 15-30 (2016).

26. Armstrong, M.J. et al. Liraglutide safety and efficacy in patients with non-alcoholic steatohepatitis (LEAN): a multicentre, double-blind, randomised, placebo-controlled phase 2 study. The Lancet 387, 679-690 (2016).

27. Baggio, L.L. \& Drucker, D.J. Glucagon-like peptide-1 receptors in the brain: controlling food intake and body weight. Journal of Clinical Investigation 124, 42234226 (2014).

28. Mukai, E. et al. GLP-1 receptor antagonist as a potential probe for pancreatic betacell imaging. Biochem Biophys Res Commun 389, 523-6 (2009).

29. Podewin, T. et al. Conditional and Reversible Activation of Class A and B G ProteinCoupled Receptors Using Tethered Pharmacology. ACS Central Science 4, 166-179 (2018).

30. Jones, B.J. et al. Potent Prearranged Positive Allosteric Modulators of the Glucagonlike Peptide-1 Receptor. ChemistryOpen, 501-505 (2017).

31. López de Maturana, R., Willshaw, A., Kuntzsch, A., Rudolph, R. \& Donnelly, D. The Isolated N-terminal Domain of the Glucagon-like Peptide-1 (GLP-1) Receptor Binds Exendin Peptides with Much Higher Affinity than GLP-1. Journal of Biological Chemistry 278, 10195-10200 (2003).

32. Ban, K. et al. Glucagon-Like Peptide (GLP)-1(9-36)Amide-Mediated Cytoprotection Is Blocked by Exendin(9-39) Yet Does Not Require the Known GLP-1 Receptor. Endocrinology 151, 1520-1531 (2010).

33. DiGruccio, M.R. et al. Comprehensive alpha, beta and delta cell transcriptomes reveal that ghrelin selectively activates delta cells and promotes somatostatin release from pancreatic islets. Molecular Metabolism 5, 449-458 (2016).

34. De Marinis, Y.Z. et al. GLP-1 Inhibits and Adrenaline Stimulates Glucagon Release by Differential Modulation of $\mathrm{N}$ - and L-Type Ca2+ Channel-Dependent Exocytosis. Cell Metabolism 11, 543-553 (2010).

35. Cabrera, $\mathrm{O}$. et al. The unique cytoarchitecture of human pancreatic islets has implications for islet cell function. Proceedings of the National Academy of Sciences of the United States of America 103, 2334-9 (2006).

36. Gustafsson, N. et al. Fast live-cell conventional fluorophore nanoscopy with ImageJ through super-resolution radial fluctuations. Nat Commun 7, 12471 (2016).

37. Sungkaworn, T. et al. Single-molecule imaging reveals receptor-G protein interactions at cell surface hot spots. Nature 550, 543-547 (2017).

38. Calebiro, D. et al. Single-molecule analysis of fluorescently labeled G-proteincoupled receptors reveals complexes with distinct dynamics and organization. Proc Natl Acad Sci U S A 110, 743-8 (2013).

39. Pansare, V., Hejazi, S., Faenza, W. \& Prud'homme, R.K. Review of LongWavelength Optical and NIR Imaging Materials: Contrast Agents, Fluorophores and Multifunctional Nano Carriers. Chem Mater 24, 812-827 (2012).

40. Scrocchi, L.A. et al. Glucose intolerance but normal satiety in mice with a null mutation in the glucagon-like peptide 1 receptor gene. Nat Med 2, 1254-8 (1996).

41. Visel, A., Rubin, E.M. \& Pennacchio, L.A. Genomic views of distant-acting enhancers. Nature 461, 199-205 (2009).

42. Filios, S.R. \& Shalev, A. $\beta$-Cell MicroRNAs: Small but Powerful. Diabetes 64, 3631 3644 (2015).

43. Akerman, I. et al. Human Pancreatic beta Cell IncRNAs Control Cell-Specific Regulatory Networks. Cell Metab 25, 400-411 (2017). 
44. Nauck, M.A. et al. Normalization of fasting hyperglycaemia by exogenous glucagonlike peptide 1 (7-36 amide) in type 2 (non-insulin-dependent) diabetic patients. Diabetologia 36, 741-4 (1993).

45. Tornehave, D., Kristensen, P., Romer, J., Knudsen, L.B. \& Heller, R.S. Expression of the GLP-1 receptor in mouse, rat, and human pancreas. J Histochem Cytochem 56, 841-51 (2008).

46. Ramracheya, R. et al. GLP-1 suppresses glucagon secretion in human pancreatic alpha-cells by inhibition of P/Q-type Ca2+ channels. Physiological Reports 6, e13852 (2018).

47. Zhang, Y. et al. GLP-1 Receptor in Pancreatic alpha Cells Regulates Glucagon Secretion in a Glucose-Dependent Bidirectional Manner. Diabetes (2018).

48. Buenaventura, T. et al. Agonist binding affinity determines palmitoylation of the glucagon-like peptide 1 receptor and its functional interaction with plasma membrane nanodomains in pancreatic beta cells. (2018).

49. Omar, B. \& Ahren, B. Pleiotropic Mechanisms for the Glucose-Lowering Action of DPP-4 Inhibitors. Diabetes 63, 2196-2202 (2014).

50. Smith, N.A. et al. Fluorescent Ca2+indicators directly inhibit the Na,K-ATPase and disrupt cellular functions. Science Signaling 11, eaal2039 (2018).

51. Naylor, J. et al. Use of CRISPR/Cas9-engineered INS-1 pancreatic beta cells to define the pharmacology of dual GIPR/GLP-1R agonists. Biochem J 473, 2881-91 (2016).

52. Zimmer, C. et al. Statistical Analysis of 3D Images Detects Regular Spatial Distributions of Centromeres and Chromocenters in Animal and Plant Nuclei. PLOS Computational Biology 6, e1000853 (2010).

53. Jaqaman, $\mathrm{K}$. et al. Robust single-particle tracking in live-cell time-lapse sequences. Nature Methods 5, 695-702 (2008).

54. Sungkaworn, T., Rieken, F., Lohse, M.J. \& Calebiro, D. High-resolution Spatiotemporal Analysis of Receptor Dynamics by Single-molecule Fluorescence Microscopy. Journal of Visualized Experiments (2014).

55. Treppiedi, D. et al. Single-Molecule Microscopy Reveals Dynamic FLNA Interactions Governing SSTR2 Clustering and Internalization. Endocrinology 159, 2953-2965 (2018).

56. Zhang, Y. et al. Cryo-EM structure of the activated GLP-1 receptor in complex with a G protein. Nature 546, 248-253 (2017). 
We thank Bettina Mathes and Alexandra Teslenko for excellent synthetic support. D.J.H. was supported by a Diabetes UK R.D. Lawrence (12/0004431) Fellowship, a Wellcome

657 Trust Institutional Support Award, MRC Confidence in Concept, MRC (MR/N00275X/1)

658 Project and Diabetes UK (17/0005681) Project Grants. ST was supported by an MRC

659 Project Grant (MR/N02589X/1). B.H. was supported by the Wellcome Trust (095101, 660200837 and 106130). A.K.L. was supported by R03 DK115990 (to A.K.L.) and Human Islet 661 Research Network UC4 DK104162 (to A.K.L.; RRID:SCR_014393). Intravital microscopy 662 core services were supported by NIH NIDDK Grant P30 DK097512 to the Indiana University 663 School of Medicine. A.T. and B.J. were funded by an MRC Project Grant (MR/R010676/1). 664 D.C. was funded by the Deutsche Forschungsgemeinschaft (SFB/Transregio 166-Project 665 C1) and a Wellcome Trust Senior Research Fellowship. This project has received funding 666 from the European Research Council (ERC) under the European Union's Horizon 2020 667 research and innovation programme (Starting Grant 715884 to D.J.H.). We thank Prof Anna 668 Gloyn (University of Oxford) for provision of reagents, Dr Birgit Koch (MPI, Heidelberg) for 669 helpful discussions on Glp $1 r^{(G E)-/}$ mice and $\mathrm{Dr}$ Jacqueline Naylor (Medlmmune) for 670 generation of parental SNAP_GLP1R-INS1 ${ }^{\text {GLP1R-/. }}$ cells.

\section{CONTRIBUTIONS}

672 J.A., K.J., T.P., J.B. and D.J.H. devised the studies. J.A., A.A., D.N., N.H.F.F., F.B.A., S.T., 673 Z.S., B.H., A.T., T.P., J.B. and D.J.H. performed experiments and analyzed data. J.A. and 674 A.B. generated novel mice. B.J.J. provided reagents. Z.K. and E.D'E. performed super675 resolution imaging. C.A.R. and A.K.L. performed in vivo imaging experiments. D.C. 676 supervised and analyzed single-molecule microscopy experiments. J.A., K.J., T.P., J.B. and 677 D.J.H. supervised the work. J.A., T.P., J.B. and D.J.H. wrote the manuscript with input from 678 all the authors.

\section{COMPETING INTERESTS}

680 The authors declare no conflict of interest. 


\section{FIGURE LEGENDS}

683

684

685

686

687

688

689

690

691

692

693

694

695

696

697

698

699

700

701

702

703

704

705

706

707

708

709

710

711

712

713

714

715

716

717

718

719

720

721

722

723

724

725

726
Figure 1: Sequence and structure of LUXendin555, LUXendin651 and LUXendin645 bound to GLP1R. LUXendins are based on the antagonist Exendin4(9-39), shown in complex with GLP1R. The label can be any dye, such as TMR (top), SiR (middle) or Cy5 (bottom) to give LUXendin555, LUXendin651 and LUXendin645, respectively. The model was obtained by using the cryo-EM structure of the activated form of GLP1R in complex with a $\mathrm{G}$ protein (pdb: $5 \mathrm{VAl})^{56}$, with the $\mathrm{G}$ protein and the $8 \mathrm{~N}$-terminal amino acids of the ligand removed from the structure while mutating $\mathrm{S} 39 \mathrm{C}$ and adding the respective linker. Models were obtained as representative cartoons by the in-built building capability of PyMOL (Palo Alto, CA, USA) without energy optimization. Succinimide stereochemistry is unknown and neglected for clarity.

Figure 2: LUXendin645 binding, signaling and labeling. a, Exendin4(9-39), its S39C mutant and LUXendin645 display similar antagonistic properties ( $n=3$ replicates). $\mathbf{b}$, LUXendin645 does not activate the GLP1R in CHO-K1-SNAP_GLP1R cells unless the positive allosteric modulator (PAM) BETP is present (Exendin4; +ve control) ( $n=3$ assays). c, LUXendin645 labels CHO-K1-SNAP_GLP1R cells with a maximal labeling achieved at $100 \mathrm{nM}$. d, LUXendin645 signal can be detected in YFP-AD293-SNAP_GLP1R but not YFP-AD293 cells (scale bar $=212.5 \mu \mathrm{m})(\mathrm{n}=3$ assays). e, Representative confocal $z$-stack (1 $\mu \mathrm{m}$ steps) showing penetration of LUXendin645 deep into a live pancreatic islet $(x-y, x-z$ and $y-z$ projections are shown) ( $n=4$ islets) (scale bar $=37.5 \mu \mathrm{m})$. f, As for (e), but twophoton z-stack (1 $\mu \mathrm{m}$ steps) showing the entire volume of an islet labeled with LUXendin645 (scale bar $=37.5 \mu \mathrm{m})(\mathrm{n}=9$ islets). $\mathbf{g}$ and $\mathbf{h}$, GLP1R is internalized in MIN6 cells when agonist activity is conferred on LUXendin645 using the positive allosteric modulator BETP (scale bar $=21 \mu \mathrm{m})(\mathrm{n}=5$ images, 693-722 cells; Student's unpaired t-test) (Bar graph shows mean \pm SEM). $\mathbf{i}$ and $\mathbf{j}$, LUXendin645 signal can be detected even following fixation and co-localizes with a specific monoclonal antibody against the GLP1R in both islets $(\mathrm{n}=$ 13 islets) and MIN6 $\beta$-cells ( $n=6$ images, 543 cells) (scale bar $=26 \mu \mathrm{m}$ ). $\mathbf{k}$, The superior signal-to-noise-ratio of LUXendin645 allows more membrane detail to be visualized compared to antibody (scale bar $=12.5 \mu \mathrm{m}$ ). Representative images are shown, with a blue bar indicating the location of intensity-over-distance measures (the islet was co-stained with LUXendin645 + antibody to allow direct comparison) ( $\mathrm{n}=13$ islets). I and $\mathbf{m}$, LUXendin645 co-localizes with the SNAP label, Surface 488, in SNAP_hGLP1R-INS1 ${ }^{\text {GLP1-/ }}$, which are deleted for the endogenous GIp1r (I). Pre-treatment with Exendin4(9-39) to internalize the GLP1R reduces LUXendin645-labeling $(\mathbf{m})$ (a wash-step was used prior to application of the label) (scale bar $=10 \mu \mathrm{m})(n=4-5$ images; 57-64 cells). Mean \pm SE are shown. ${ }^{* *} \mathrm{P}<0.01$.

Figure 3: LUXendin645 is highly specific for the GLP1R. a, Schematic showing sgRNA targeting strategy for the production of Glp $1 r^{(G E)-/-}$ mice. The sgRNA used targeted Glp1r and the double-strand break mediated by Cas9 lies within exon1 (capital letters); intron shown in gray. b, Glp $1 r^{(G E)-r}$ animals harbor a single-nucleotide deletion, as shown by sequencing traces. c, Body weights were similar in male 8 weeks old Glp $1 r^{+/+}, G / p 1 r^{(G E)+/}$ and $G l p 1 r^{(G E)-/-}$ littermates ( $n=4-8$ animals; one-way ANOVA with Bonferroni's post hoc test; $F=0.7982$, $\mathrm{DF}=2)($ Bar graph shows mean \pm SEM) d, The incretin-mimetic Exendin4(1-39) $(10 \mathrm{nM})$ is 
unable to significantly potentiate glucose-stimulated insulin secretion in $G / p 1 r^{(G E)-/}$ islets $(\mathrm{n}=$ 6 replicates; two-way ANOVA with Sidak's post hoc test; $F=14.96$, DF $=2$ for $G / p 1 r^{+/+}, F=$ 2.968, DF $=2$ for Glp1 $r^{(G E)-/}$ ) (Bar graph shows mean \pm SEM) e, Liraglutide (Lira) does not stimulate cAMP beyond vehicle (Veh) control in Glp $1 r^{(G E)-\gamma}$ islets, measured using the FRET probe Epac2-camps (traces represent mean \pm SEM) ( $n=14-17$ islets). $f$, cAMP area-underthe-curve (AUC) quantification showing absence of significant Liraglutide-stimulation in Glp1r ${ }^{(G E)-/}$ islets ( $\mathrm{n}=14-17$ islets; Kruskal-Wallis test with Dunn's post hoc test; KruskalWallis statistic $=7.6$, DF $=2$ ) (Box and Whiskers plot shows min-max and median) (representative images displayed above each bar). g, LUXendin645 and GLP1R antibody labeling is not detectable in Glp1 $r^{(G E)-~}$ islets (scale bar $\left.=40 \mu \mathrm{m}\right)(\mathrm{n}=12-14$ islets for each genotype). ${ }^{*} \mathrm{P}<0.05,{ }^{* *} \mathrm{P}<0.01$ and $\mathrm{NS}$, non-significant.

Figure 4: LUXendin645 reveals GLP1R expression in a subpopulation of a-cells. a-c, LUXendin645 labeling is widespread throughout the intact islet, co-localizing predominantly with $\beta$-cells (a) and $\delta$-cells (b), but less so with $\alpha$-cells (c) stained for insulin, somatostatin and glucagon, respectively ( $n=7-9$ islets) (scale bar $=26 \mu \mathrm{m}$ ). d, Following dissociation of islets into cell clusters, LUXendin645 labeling can be more accurately quantified (arrows highlight cells selected for zoom-in) (scale bar $=26 \mu \mathrm{m}$ ). e, Zoom-in of (d) showing a LUXendin645- (left) and LUXendin645+ (right) $\alpha$-cell (arrows highlight non-labeled cell membrane, which is not bounded by a $\beta$-cell) (scale bar $=26 \mu \mathrm{m}$ ). $\mathbf{f}$, Box-and-whiskers plot showing proportion of $\beta$-cells (INS) and $\alpha$-cells (GLU) co-localized with LUXendin645 ( $\mathrm{n}=$ 5-6 images, 12 cell clusters) (Max-min shown together with the median). $\mathbf{g}$, Ins $1 C r e^{T h o r} ; R 26^{m T / m G}$ dual fluorophore reporter islets express tdTomato until Cre-mediated replacement with mGFP, allowing identification of $\beta$-cells ( $80 \%$ of the islet population) and non- $\beta$-cells for live imaging (scale bar $=26 \mu \mathrm{m}$ ). LUXendin645 highlights GLP1R expression in nearly all $\beta$-cells but relatively few non- $\beta$-cells ( $n=24$ islets, 809 cells). $\mathbf{h}$, As for ( $\mathbf{g}$ ), but a zoom-in showing GLP1R expression in some non- $\beta$-cells (left) together with quantification (right) (arrows show LUXendin645-labeled non- $\beta$ cells) (scale bar $=5 \mu \mathrm{m}$ ) (Box and Whiskers plot shows min-max and median).

Figure 5: LUXendin651 and LUXendin645 allow nanoscopic detection of GLP1R distribution and dynamics. a, LUXendin645 allows super-resolution snapshots of MIN6 $\beta$ cells using widefield microscopy combined with Super-Resolution Radial Fluctuations (SRRF) ( $n=3$ images) (scale bar $=10 \mu \mathrm{m}$ ). $\mathbf{b}$ and $\mathbf{c}$, Confocal and STED snapshots of endogenous GLP1R in LUXendin651-treated MIN6 cells at $\sim 50 \mathrm{~nm}$ axial resolution. Note the presence of punctate GLP1R expression as well as aggregation/clustering in images captured above (b) and close to the coverslip (c) using STED microscopy ( $n=3$ images, 15 cells) (scale bar $=2 \mu \mathrm{m}$ ). $\mathbf{d}$ and $\mathbf{e}$, Spatial analysis of GLP1R expression patterns using the F-function (d) and G-function (e) show a non-random distribution (red line) versus a random model (black line; 95\% confidence interval shown). f, Approximately 1 in 4 MIN6 $\beta$-cells possess highly concentrated GLP1R clusters (Bar graph shows mean \pm SEM) $(n=3$ images, 15 cells). g, Single molecule microscopy and tracking of LUXendin645- and LUXendin651labeled GLP1R ( $\mathrm{n}=2$ movies) (scale bar $=3 \mu \mathrm{m}$ ). $\mathbf{h}$, Mean square displacement (MSD) analysis showing different GLP1R diffusion modes (representative trajectories are displayed) (scale bar $=1 \mu \mathrm{m})$. 
773 Figure 6: LUXendin555 displays agonist properties and allows in vivo labeling of 774 islets. a and b, LUXendin555 labels YFP-AD293_SNAP-GLP1R (a) but not YFP-AD293 (b) 775 controls $(n=3-4$ assays) (10x scale bar $=21 \overline{3} \mu \mathrm{m} ; 100 x$ scale bar $=21 \mu \mathrm{m})$. c, High resolution snapshot of LUXendin555-labeling in MIN6 $\beta$-cells showing a punctate staining pattern in the cytosol ( $\mathrm{n}=8$ images, 142 cells) (scale bar $=9 \mu \mathrm{m}$ ). $\mathbf{d}$, Surface GLP1R expression is reduced in LUXendin555- compared to LUXendin645-treated islets (representative images shown above each bar) ( $n=5$ islets; Student's unpaired t-test) (Bar graph shows mean \pm SEM) (scale bar $=17 \mu \mathrm{m})$. e, LUXendin555 potently increases cAMP levels in YFP-AD293_SNAP-GLP1R but not YFP-AD293 cells ( $\mathrm{n}=3$ assays). $\mathbf{f}$, Allosteric modulation with BETP increases agonist activity of LUXendin555 ( $\mathrm{n}=3$ assays). $\mathbf{g}$, Schematic depicting the two-photon imaging set up for visualization of the intact pancreas in mice. $\mathbf{h}$, Representative image showing that LUXendin555 labels cell membranes in an islet surrounded by the vasculature in vivo ( $\mathrm{n}=2$ islets from 1 mouse) (scale bar $=50 \mu \mathrm{m})$. Mean \pm SE are shown. ${ }^{* *} P<0.01$. 

S39C-Ex4(9-39) $\quad \mathrm{H}_{2} \mathrm{~N}$ - D LSKQM EEEAV RLFIE WLKNG GPSSG APPPC $-\mathrm{NH}_{2}$
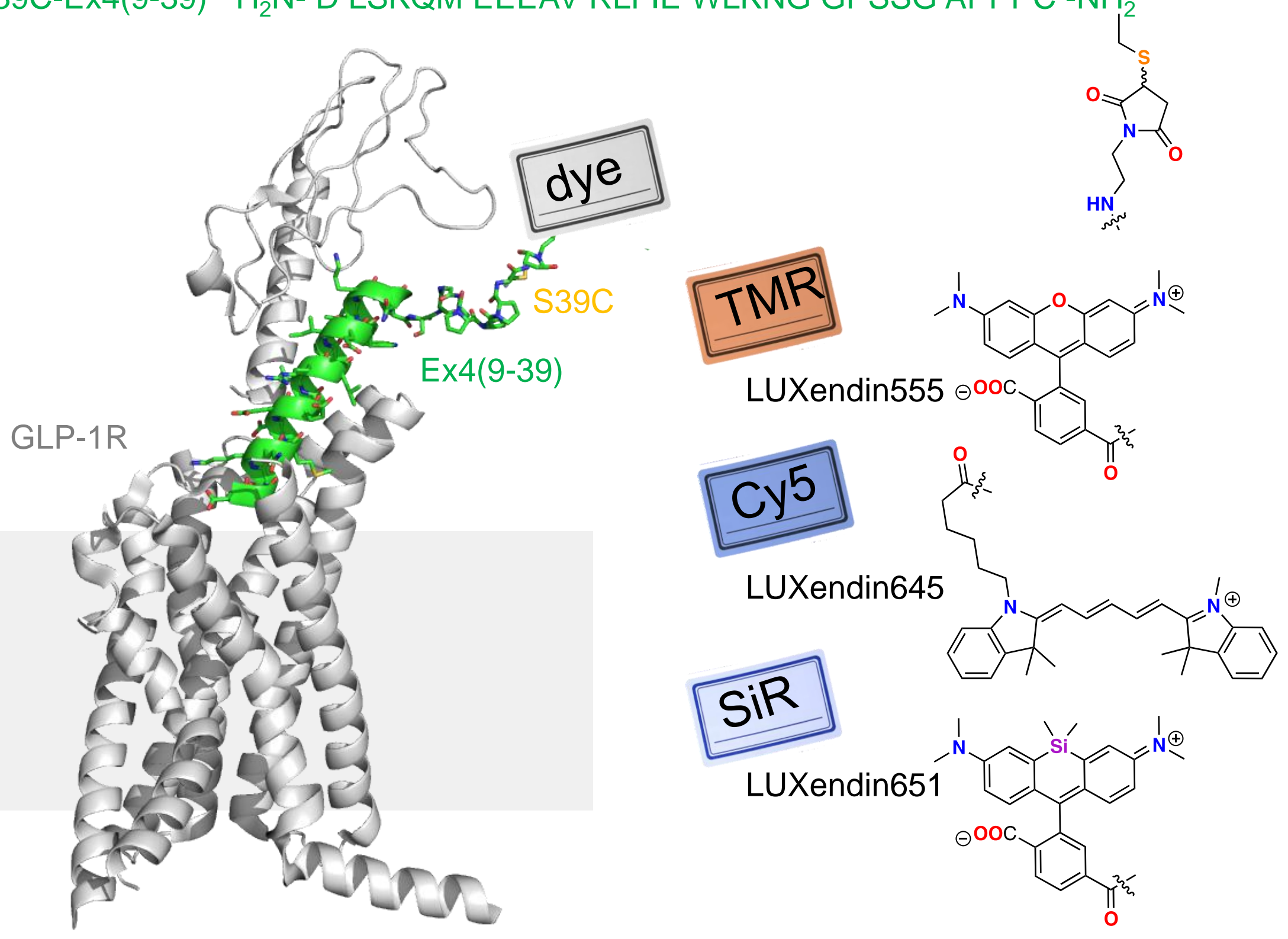

LUXendin651

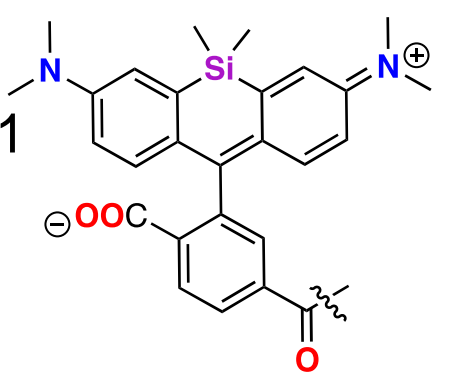



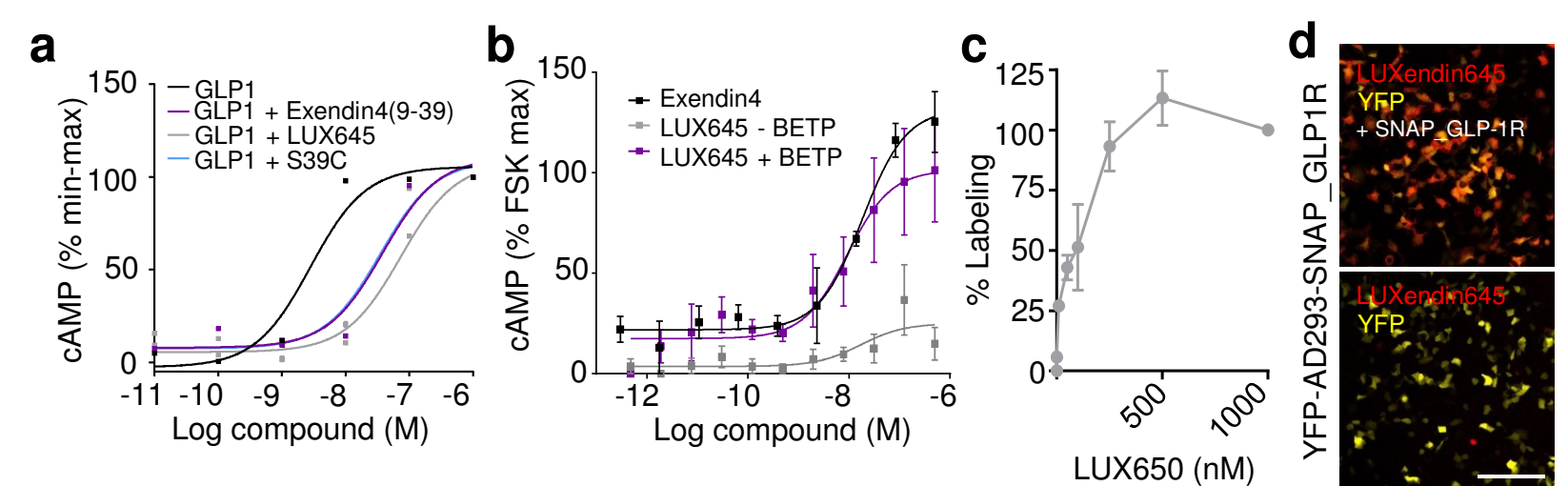

Figure 2
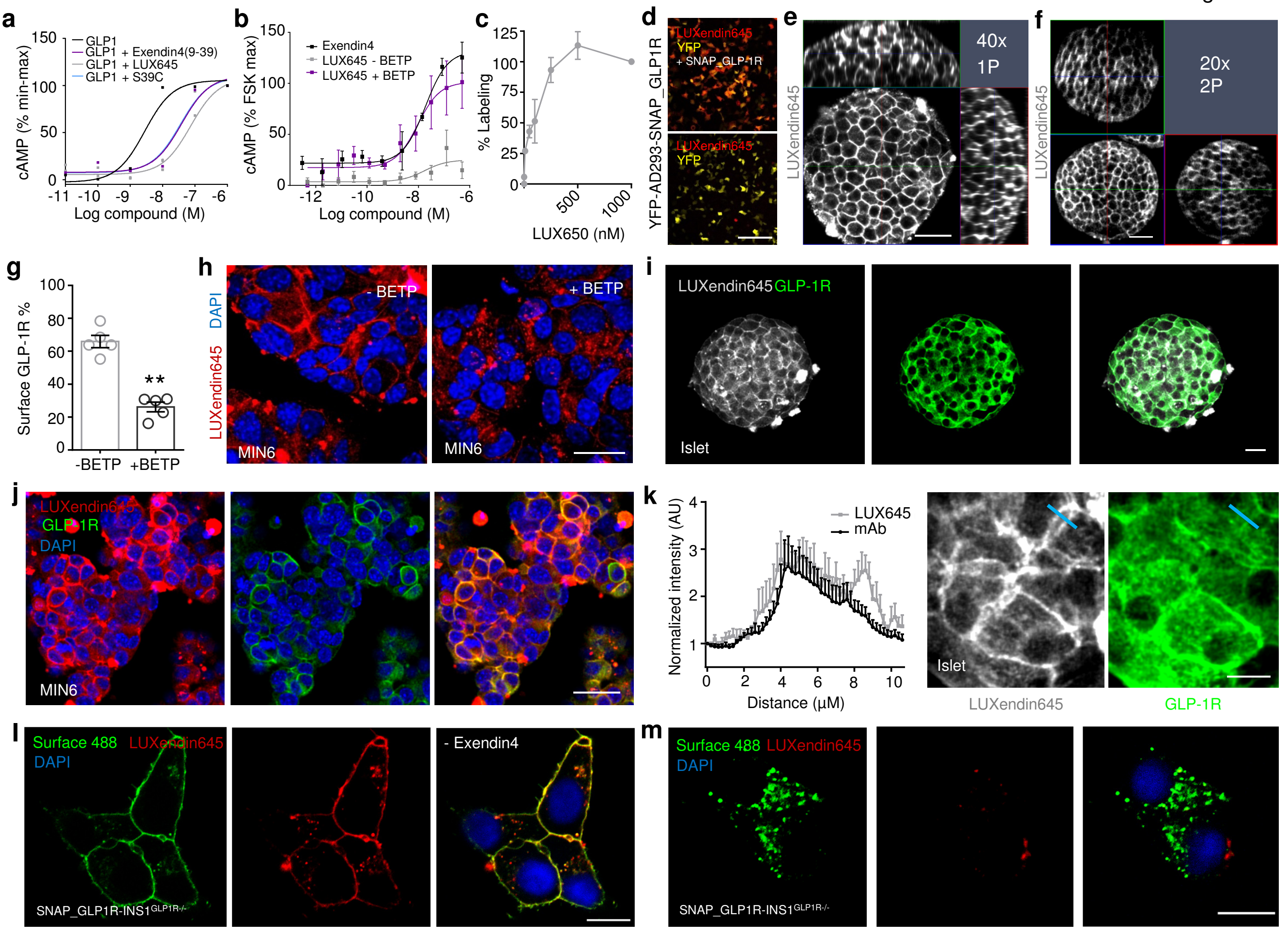
Figure 3

a
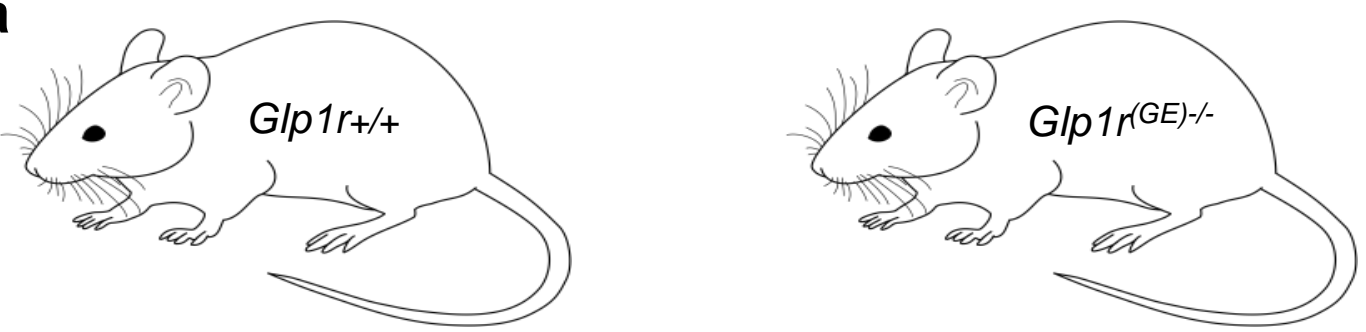

5' TGGCCAGCACCCCAAGCCTCCTGCGCCTGGCGCTCCTGCTGCTCGGGGCGG TGGGCAGGGCCGGCCCCCGCC|CTCAGgtgagecctgggaaccecggtg $\mathbf{3}$

5' $\underline{A G G G C C G G C C C C C G C C} \mid \underline{C U C}+$ scaffold 3'

b

GCTA

bioRxiv preprint doi: https://doi.org/10.1101/557132; this version posted May 8, 2019. The copyright holder for this preprint (which was not certified by peer review) is the author/funder, who has granted pioRxiv a license to display the preprint in perpetuity. It is made available

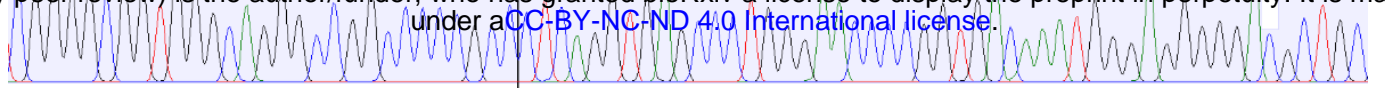

Glp $1 r^{(G E)--~}$

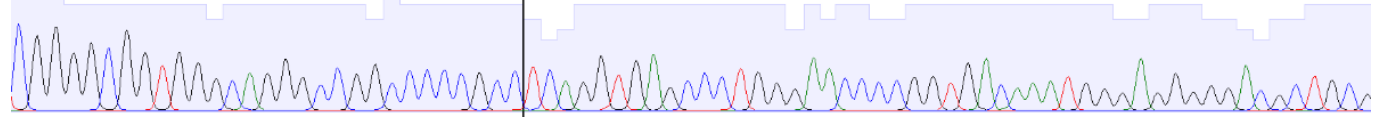
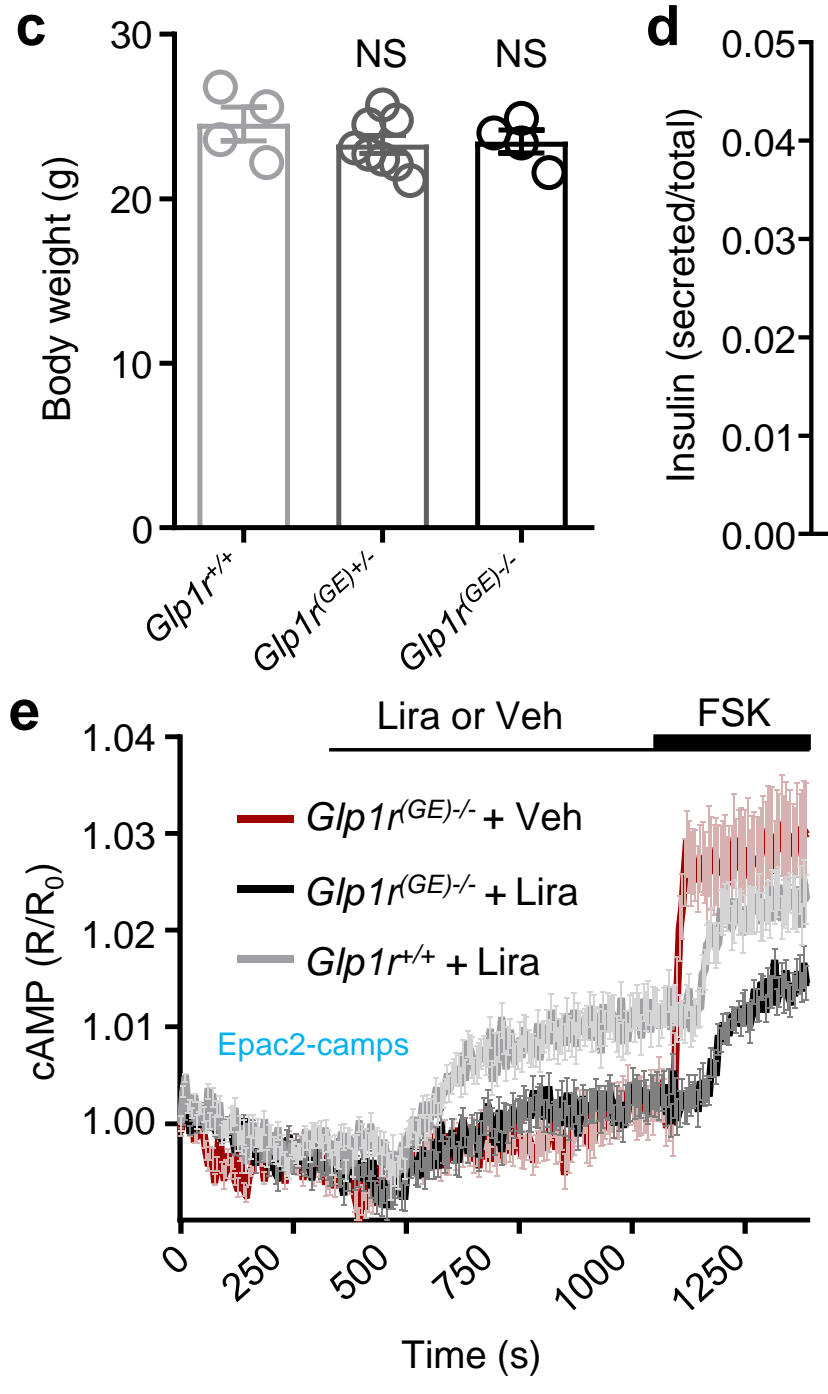
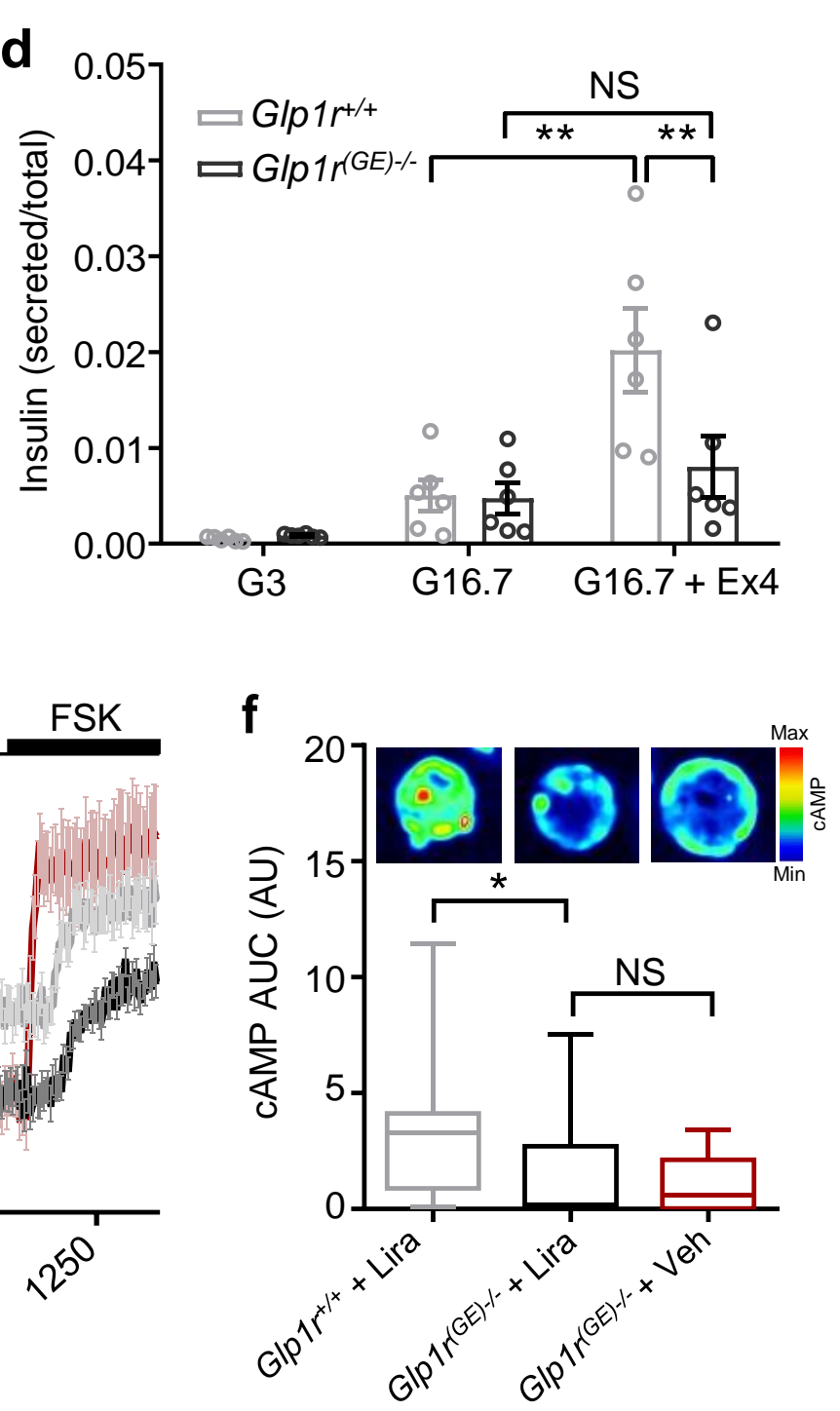
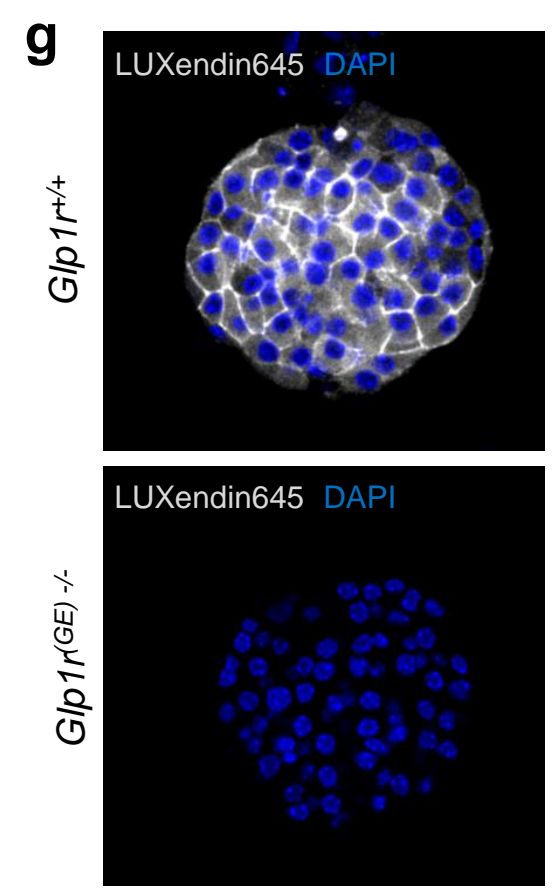
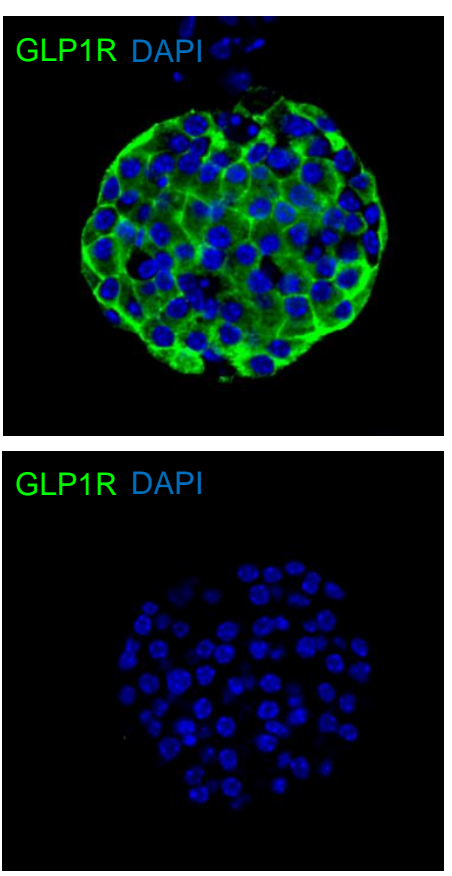
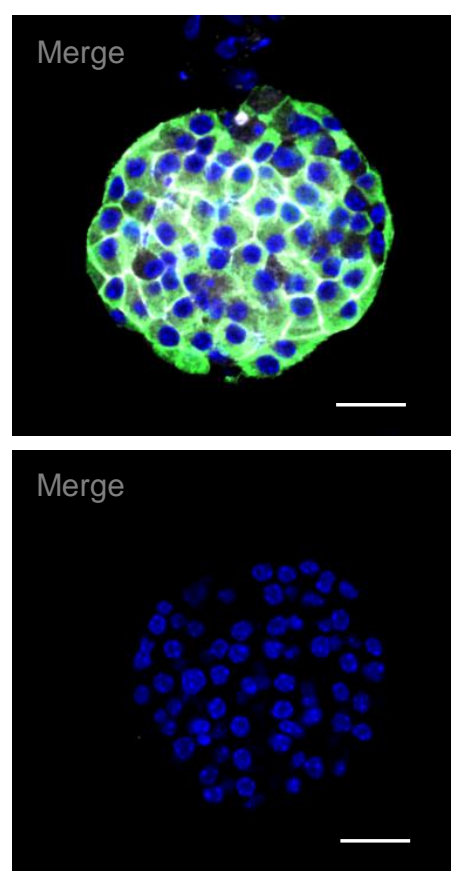
Figure 4

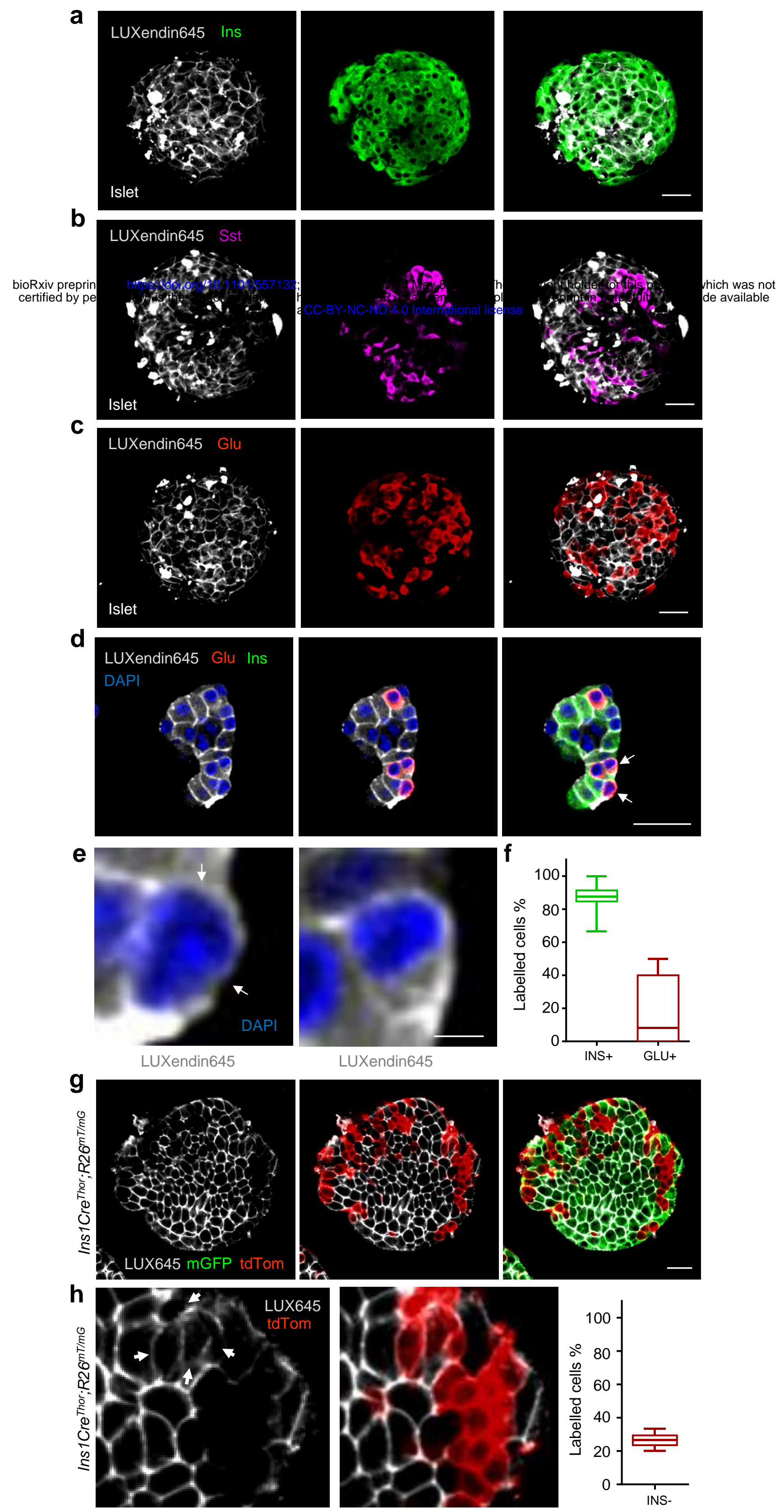


a

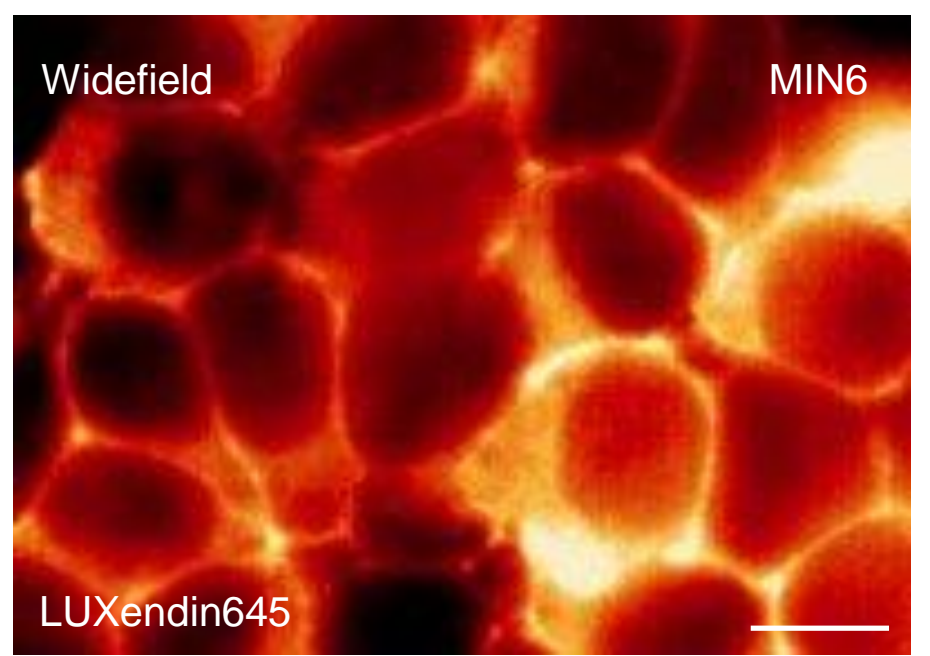

b

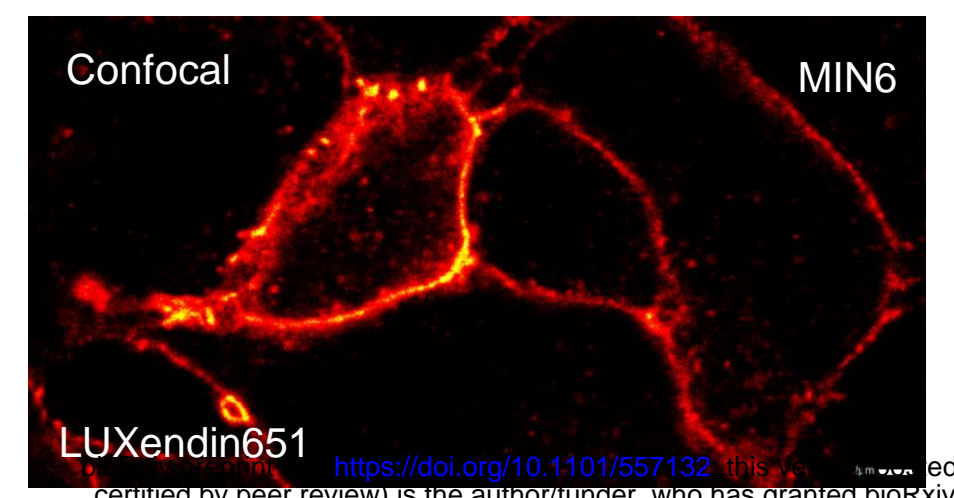

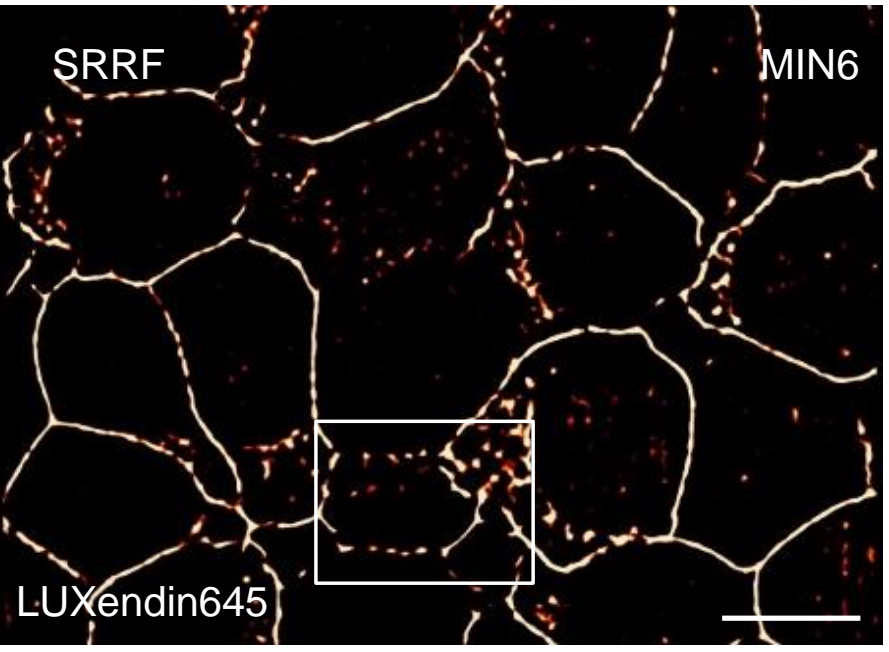

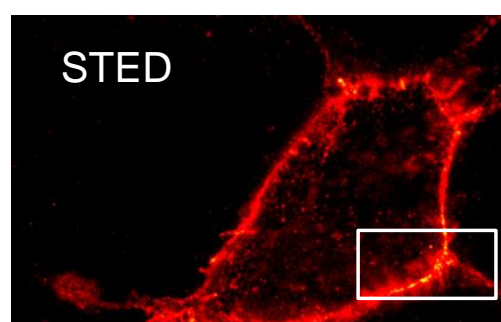

LUXendin651

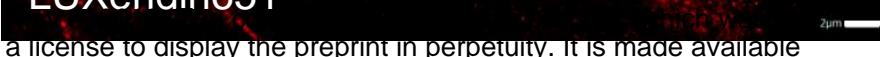

C

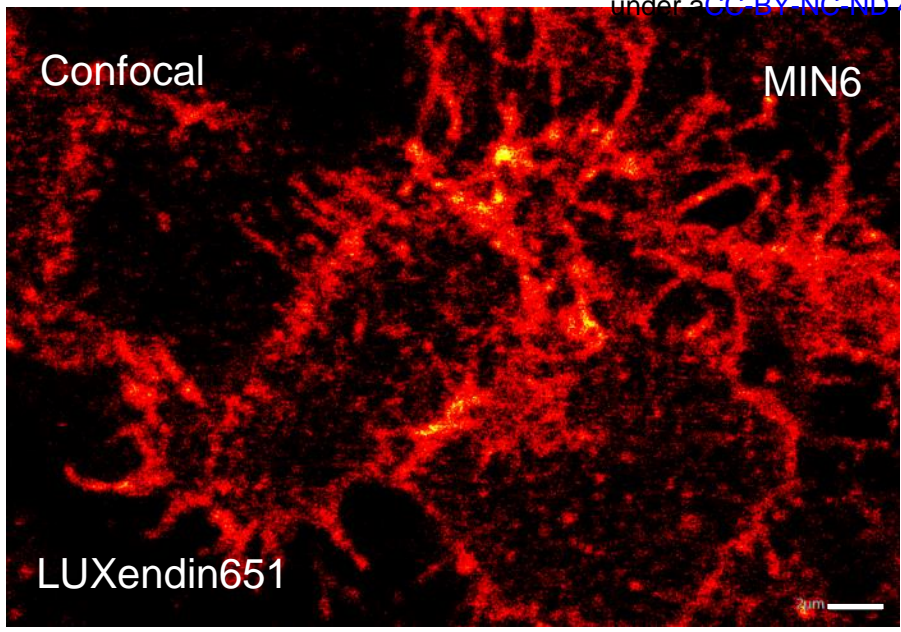

d

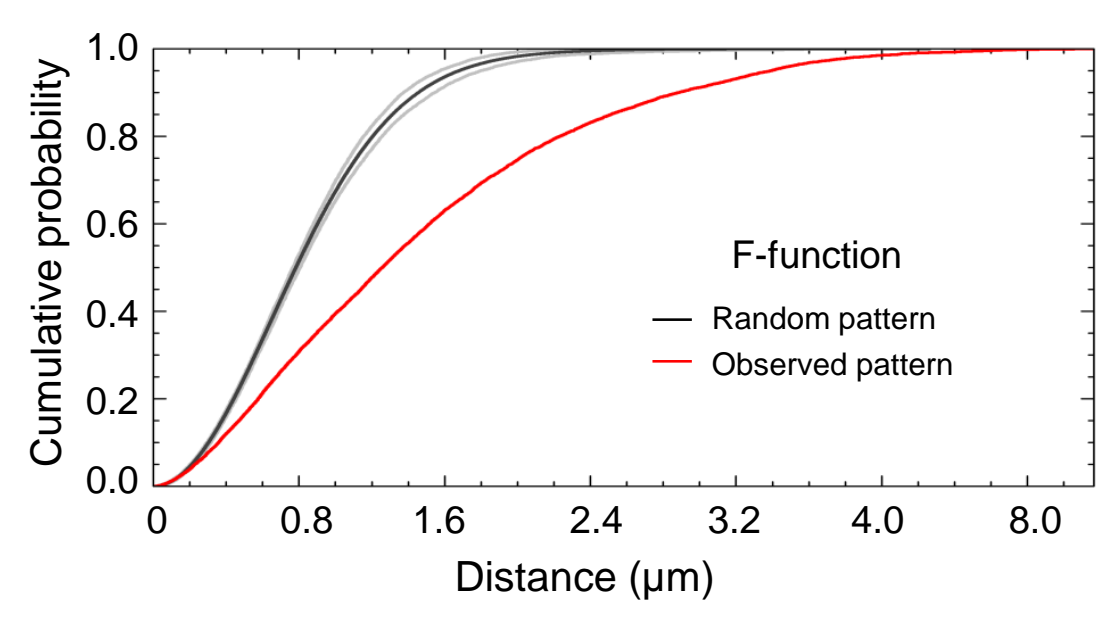

e
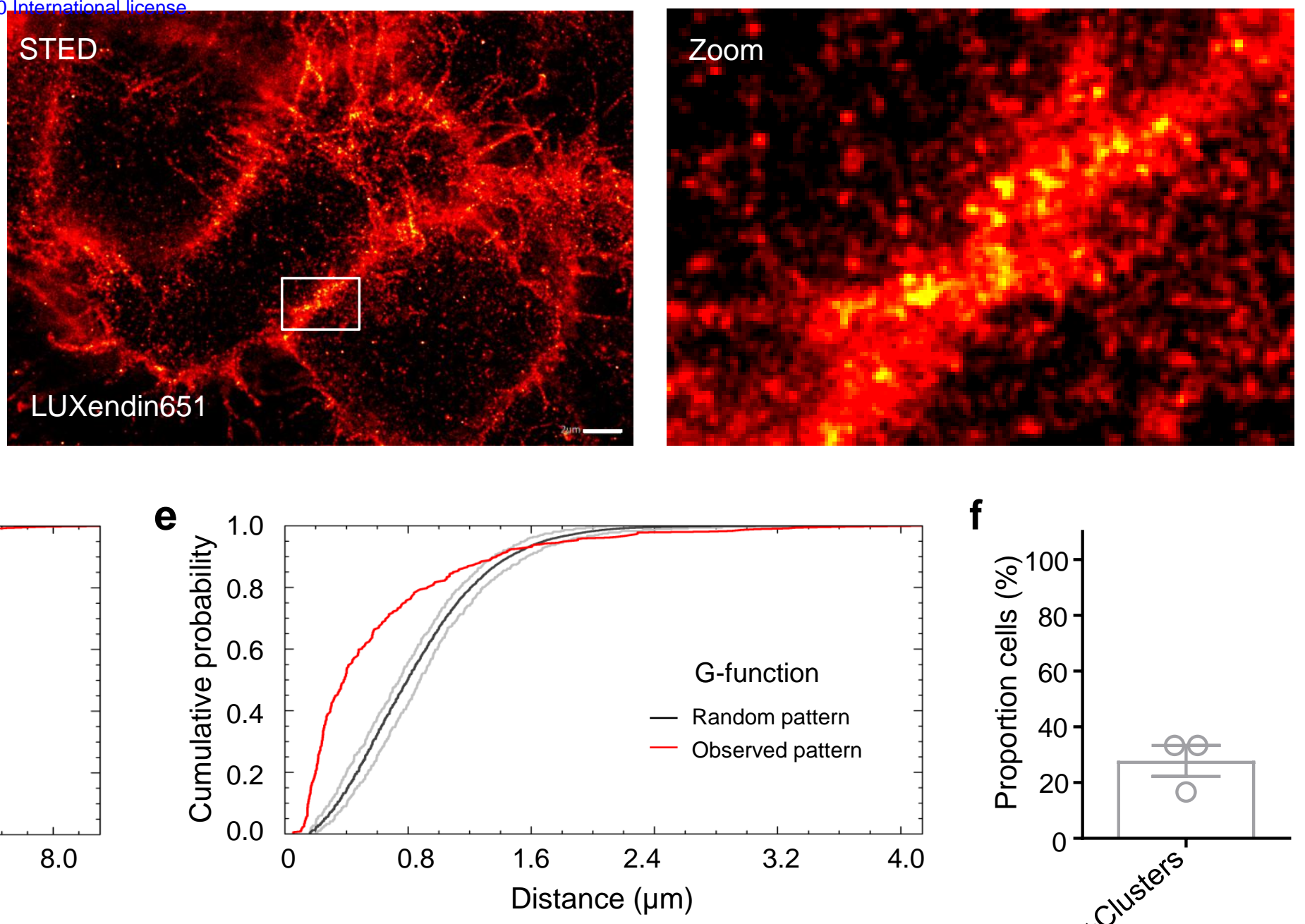

f

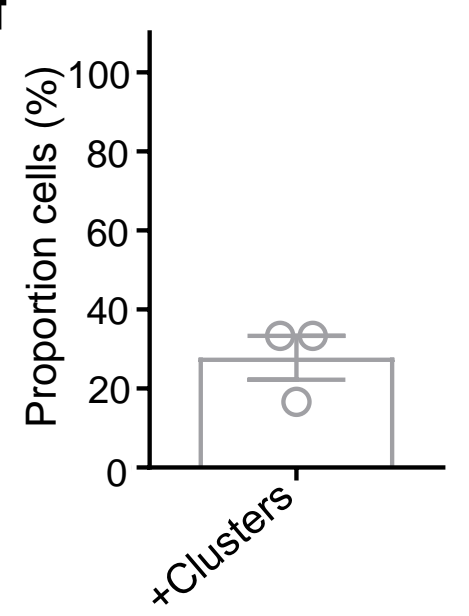

CHOK1-SNAP GLP1R

h

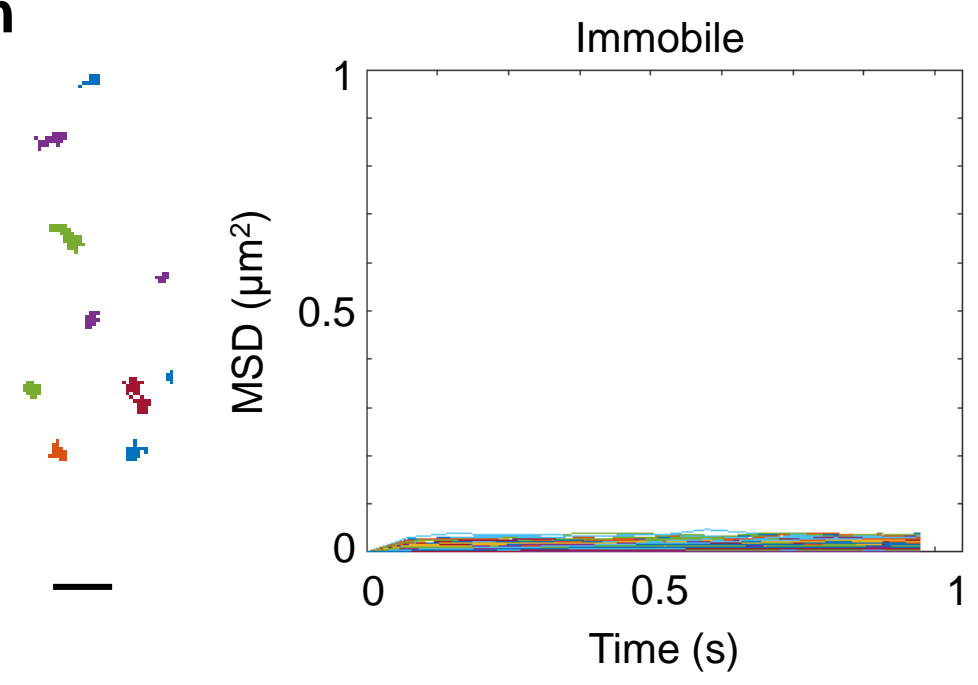

CHO-K1-SNAP GLP1R

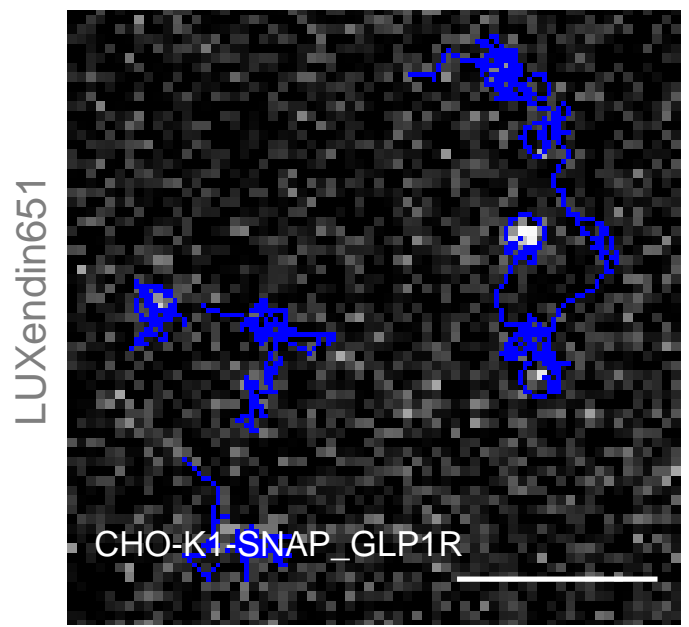

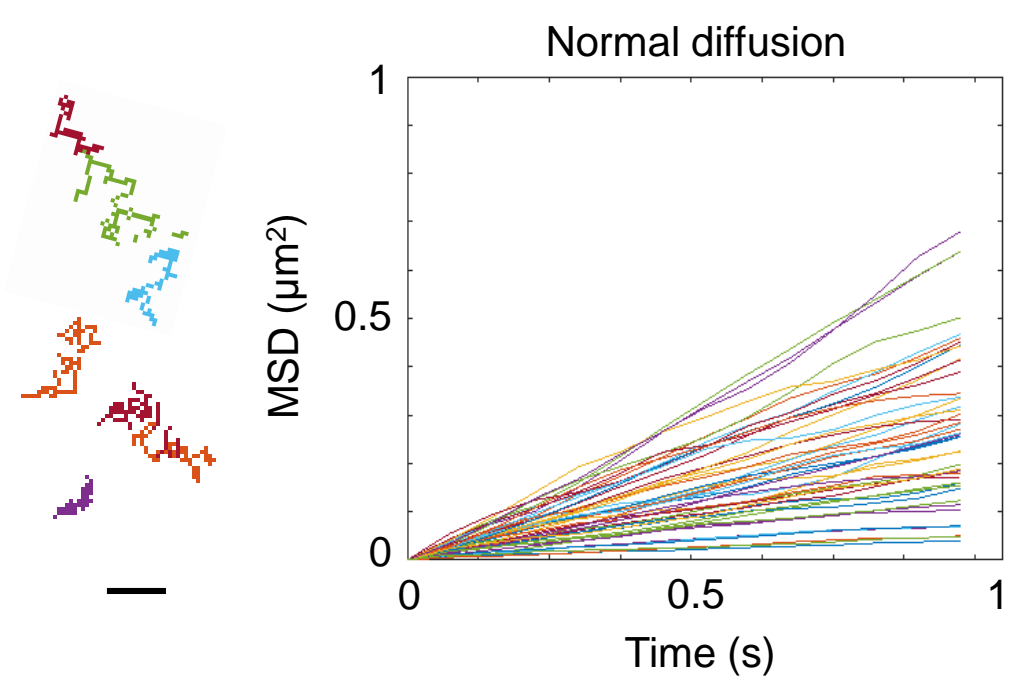

Sub-diffusion

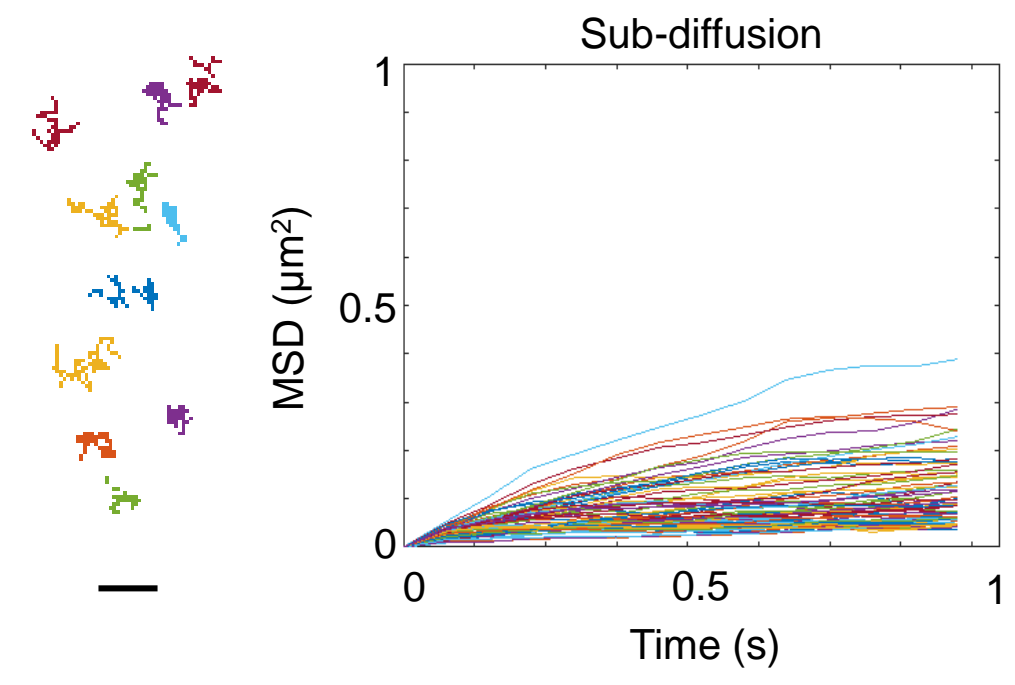

Super-diffusion

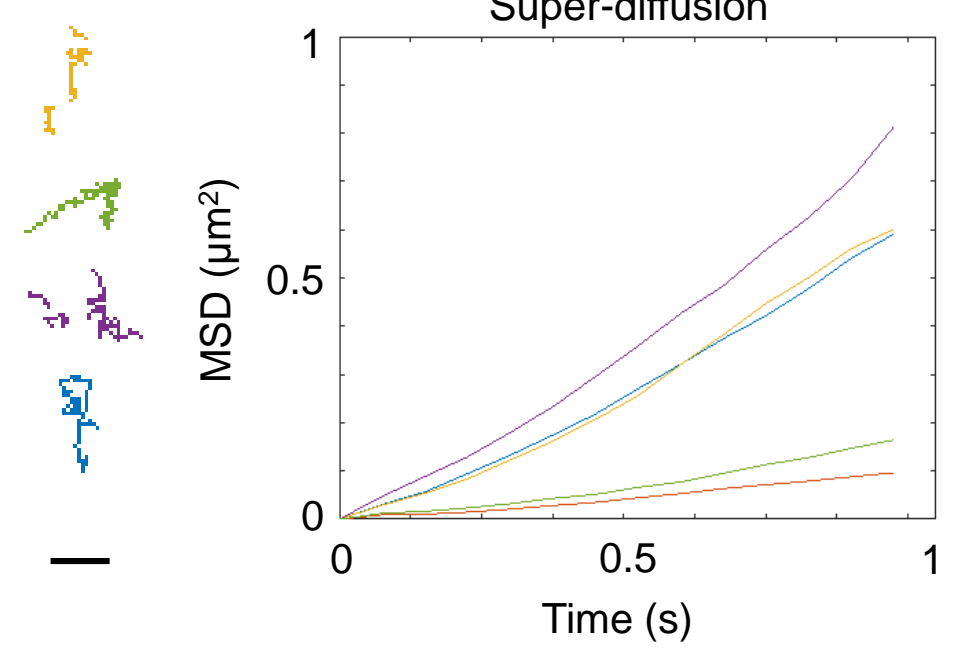


Figure 6
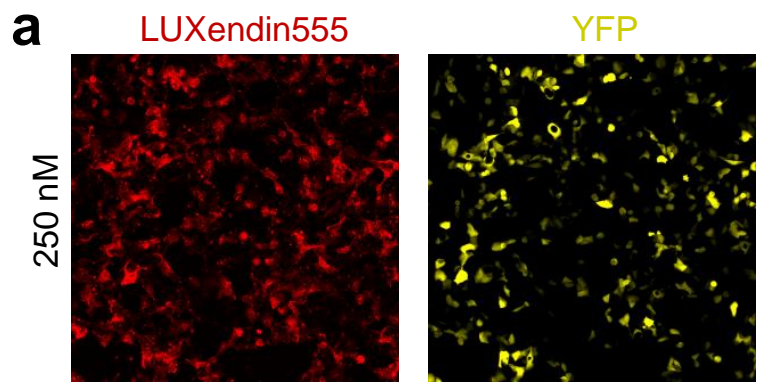

Merge
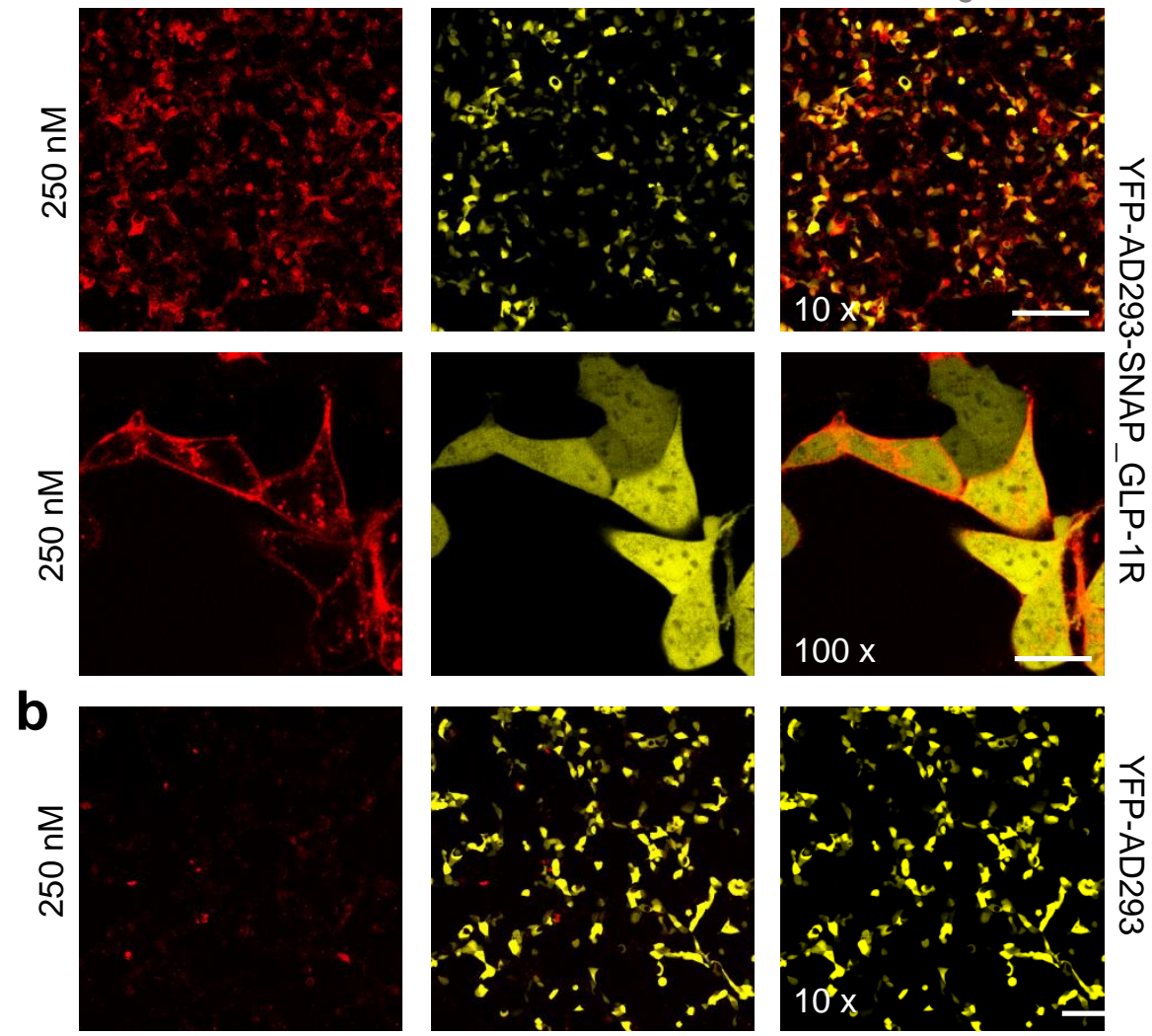

C
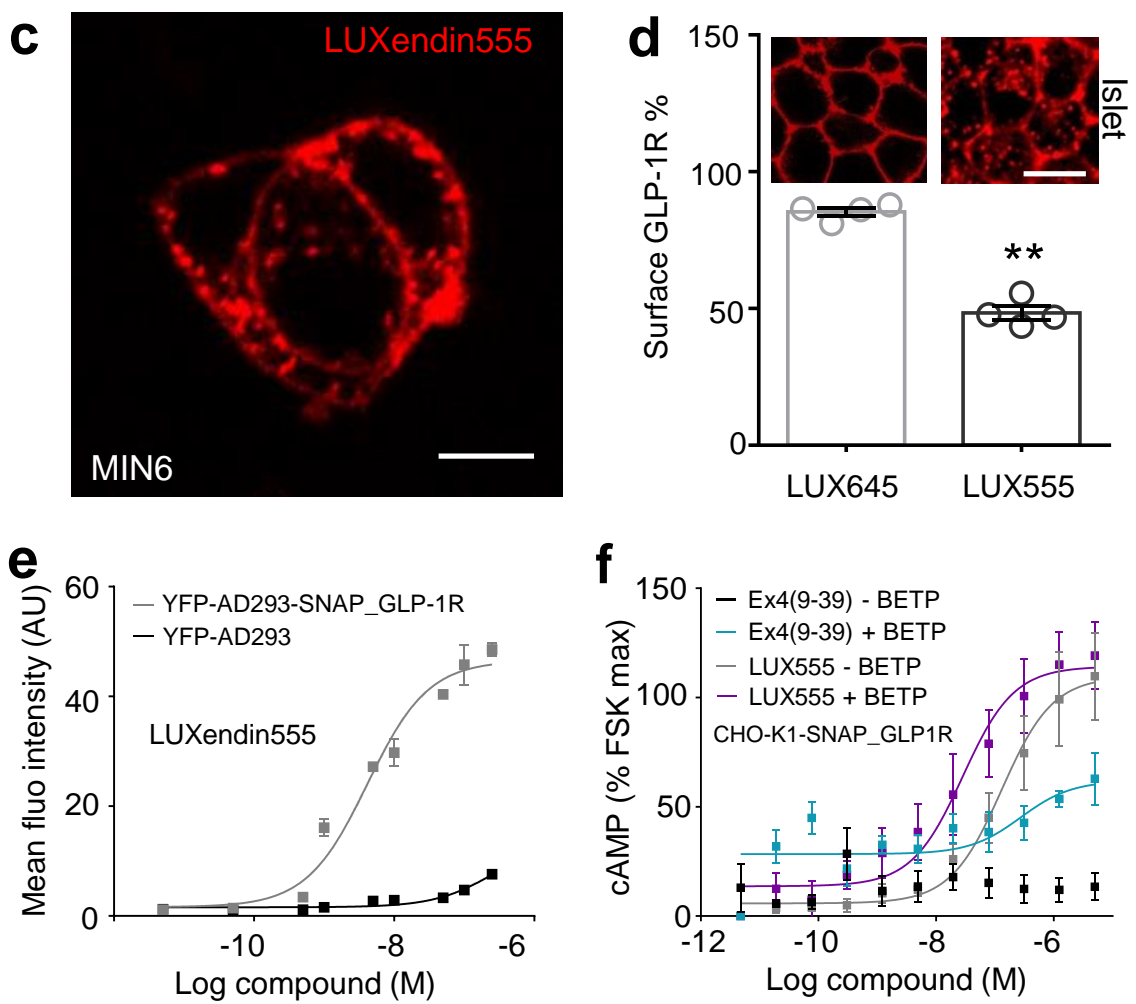

g

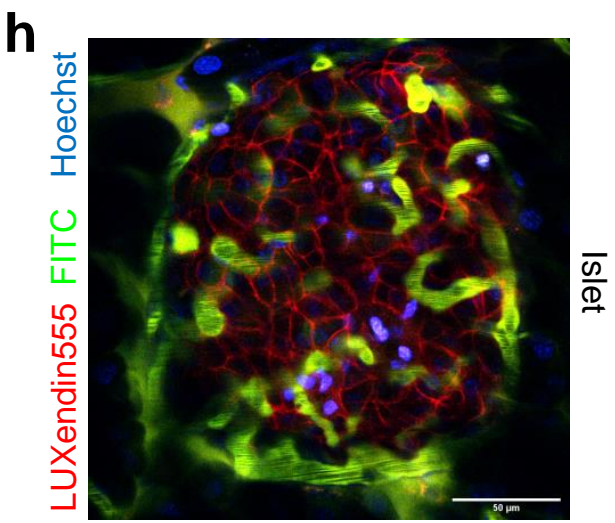

